\title{
Adult Neurogenesis Requires Smad4-Mediated Bone Morphogenic Protein Signaling in Stem Cells
}

\author{
Dilek Colak, ${ }^{1}$ Tetsuji Mori, ${ }^{1}$ Monika S. Brill, ${ }^{1,6}$ Alexander Pfeifer, ${ }^{2}$ Sven Falk, ${ }^{3}$ Chuxia Deng, ${ }^{4}$ Rui Monteiro, ${ }^{5}$ \\ Christine Mummery, ${ }^{5}$ Lukas Sommer, ${ }^{3}$ and Magdalena Götz ${ }^{1,6}$ \\ ${ }^{1}$ Helmhotz Center Munich, German Research Center for Environmental Health, Institute for Stem Cell Research, 85764 Neuherberg/Munich, Germany, \\ ${ }^{2}$ Institute for Pharmacology and Toxicology, University of Bonn, 53113 Bonn, Germany, ${ }^{3}$ Institute of Anatomy, University of Zurich, CH-8057 Zurich, \\ Switzerland, ${ }^{4}$ Genetics of Development and Disease Branch, National Institute of Diabetes and Digestive and Kidney Diseases, National Institutes of Health, \\ Bethesda, Maryland 20892, 5Developmental Biology, Hubrecht Institute, 3584CT Utrecht, Netherlands, and ${ }^{5}$ Physiological Genomics, University of Munich, \\ 80336 Munich, Germany
}

In the mammalian brain, neurogenesis continues only in few regions of the forebrain. The molecular signals governing neurogenesis in these unique neurogenic niches, however, are still ill defined. Here, we show that bone morphogenic protein (BMP)-mediated signaling is active in adult neural stem cells and is crucial to initiate the neurogenic lineage in the adult mouse subependymal zone. Conditional deletion of Smad4 in adult neural stem cells severely impairs neurogenesis, and this is phenocopied by infusion of Noggin, an extracellular antagonist of BMP. Smad4 deletion in stem, but not progenitor cells, as well as Noggin infusion lead to an increased number of Olig2-expressing progeny that migrate to the corpus callosum and differentiate into oligodendrocytes. Transplantation experiments further verified the cell-autonomous nature of this phenotype. Thus, BMP-mediated signaling via Smad4 is required to initiate neurogenesis from adult neural stem cells and suppress the alternative fate of oligodendrogliogenesis.

Key words: neural stem cells; Olig2; Dlx2; neurogenesis; oligodendrocytes; transplantation

\section{Introduction}

Progenitors existing in the parenchyma of the adult CNS do not generate neurons, even after brain injury (Horner et al., 2002; Buffo et al., 2005) with the exception of cells in the adult stem cell niches, the subependymal zone (SEZ) and subgranular zone (SGZ) in the dentate gyrus (Ming and Song, 2005). Astroglia and radial glia respectively act as stem cells in these niches and generate transit-amplifying precursors (TAPs) that then give rise to neuroblasts (Alvarez-Buylla et al., 2001). The adult neural stem cell niches form a unique neurogenic environment that is sufficient to instruct some progenitors isolated from the adult spinal cord toward neurogenesis (Shihabuddin et al., 2000). However, despite the potent function of this niche, we still know little about the niche signals governing neurogenesis.

Indeed, the adult SEZ retains many developmental character-

Received Sept. 24, 2007; revised Nov. 19, 2007; accepted Dec. 1, 2007.

We are very grateful to Stefan Karlsson for sharing the Tgfbr2fl/fl mouse line, to Christopher Linington for the MOG antibody, and to Masato Nakafuku for the Olig2VP16 construct. We thank the Munich Center for Integrated Protein Science. We also thank Benedikt Berninger, Annalisa Buffo, Marcos Costa, Leda Dimou, Leanne Godinho, Chichung Lie, Jovica Ninkovic, and Hermann Rohrer for very helpful discussions and comments on this manuscript, and Andrea Steiner-Mezzadri, Angelika Waiser, and Detlef Franzen for excellent technical assistance.

Correspondence should be addressed to Dr. Magdalena Götz, Gesellschaft für Strahlung und Umweltforschung, Institute for Stem Cell Research, Ingolstädter Landstrasse 1, 85764 Neuherberg/Munich, Germany. E-mail: magdalena.goetz@gsf.de.

T. Mori's present address: Department of Anatomy and Cell Science, Kansai Medical University, 10-15 Fumizonocho, Moriguchi, Osaka 570-8506, Japan.

R. Monteiro's present address: Molecular Haematology Unit, Weatherall Institute of Molecular Medicine, University of Oxford, Oxford OX3 9DS, UK.

D0I:10.1523/JNEUROSCI.4374-07.2008

Copyright $\odot 2008$ Society for Neuroscience $\quad 0270-6474 / 08 / 280434-12 \$ 15.00 / 0$ istics maintaining the expression of specific extracellular matrix components and growth factors (Gates et al., 1995; Ninkovic and Gotz, 2007) including factors that regulate stem cell maintenance, such as PEDF (pigment epithelium-derived factor), Sonic Hedgehog, and galectin (Ramirez-Castillejo et al., 2006; Sakaguchi et al., 2006; Balordi and Fishell, 2007). The platelet-derived growth factor (PDGF) also affects astrocytes with stem cell properties that express the PDGF receptor $\alpha$ (PDGFR $\alpha$ ) (Jackson et al., 2006) but rather promotes oligodendrogliogenesis than selfrenewal. Thus, in addition to a recently described neurogenic role of BDNF (Young et al., 2007), still little is known about extrinsic factors promoting neurogenesis in the SEZ.

On the contrary, more is known about intrinsic fate determinants of adult neurogenesis, such as the transcription factors Pax6 (Hack et al., 2005; Kohwi et al., 2005) and Mash1 (Parras et al., 2004). Conversely, Olig2 promotes oligodendrogenesis and rather blocks neurogenesis in the SEZ (Hack et al., 2005). Because these transcription factors are expressed in neuroblasts and the transit-amplifying precursors, the obvious question is how expression of these factors, promoting either the neurogenic or the oligodendrogliogenic lineage, is regulated. Previous analysis suggested that the bone morphogenic protein (BMP) signaling would inhibit neurogenesis and secretion of Noggin from the ependymal cells was crucial to allow neurogenesis in the adult SEZ (Lim et al., 2000). However, overexpression of BMP receptor 1a in the postnatal SEZ did not affect neurogenesis (Coskun et al., 2001). Thus, the exact role of this versatile signaling pathway exerting multiple diverse roles in the developing nervous system 
has yet to be resolved in relation to adult neurogenesis. Indeed, it has recently been shown that the same signaling molecule, Sonic Hedgehog, may exert different effect on adult neural stem cells, TAPs, or neuroblasts, respectively (Balordi and Fishell, 2007).

Here, we examined the activity and function of BMPmediated signaling in the adult SEZ and show that this pathway is active and required in adult SEZ stem cells to allow neurogenesis and inhibit oligodendrogliogenesis.

\section{Materials and Methods}

Animals. In all experiments, 9- to 10-week-old animals were used. The Smad4 floxed/floxed mouse line (Yang et al., 1998) was received on a 129/FVB and Black Swiss background and crossed to C57BL/6/J. GLAST: CreERT2 mice, BRE-EGFP mice (R. Monteiro, S. M. Chuva da Sousa Lopes, C. Mummery, unpublished observations) and Tgfbr2 floxed/ floxed mice (Leveen et al., 2002) were maintained on C57BL/6/J background. hGFAP-eGFP mouse line (Nolte et al., 2001) was received and maintained on CD1 background.

Tamoxifen administration. Tamoxifen (Sigma, St. Louis, MO; T-5648) was dissolved in corn oil (Sigma; C-8267) at $20 \mathrm{mg} / \mathrm{ml}$, and $1 \mathrm{mg}$ was injected intraperitoneally twice a day for 5 consecutive days (Mori et al., 2006). Animals were killed either 10 or $21 \mathrm{~d}$ after the end of tamoxifen application.

Neurosphere assay. SEZ of GLAST:CreERT2/Smad4wt/wt or Smad4wt/fl as controls and GLAST:CreERT2/Smad4fl/fl were dissected immediately or $21 \mathrm{~d}$ after the end of tamoxifen application, dissociated as previously described (Johansson et al., 1999; Berninger et al., 2007), and cultured at low density ( 10 cells/ $\mu$ l) to ensure the clonal origin of neurospheres (Morshead et al., 1994). Secondary neurospheres were counted $7 \mathrm{~d}$ after passage.

Histological procedures and 5-bromodeoxyuridine labeling. For immunohistochemistry, animals were deeply anesthetized and then transcardially perfused with $4 \%$ paraformaldehyde in PBS. Brains were cyroprotected, cut, and stained according to standard protocols. Primary antibodies were directed against the following: phospho-Smad1/5/8 (rabbit; Cell Signaling Technology, Beverly, MA), doublecortin (DCX) (guinea pig; Chemicon, Temecula, CA), 5-bromodeoxyuridine (BrdU) (rat; Abcam, Cambridge, MA), glial fibrillary acidic protein (GFAP) (mouse; DakoCytomation, High Wycombe, UK; or rabbit; Sigma), Dlx2 (rabbit; Chemicon), Olig2 (rabbit; Chemicon), Mash1 (mouse; kind gift from F. Guillemot, National Institute for Medical Research, Mill Hill, London, UK), S100 $\beta$ (mouse; Sigma), PDGFR $\alpha$ (rabbit; Spring Biosciences), CNPase (mouse; Sigma), CC1 (mouse; Calbiochem, La Jolla, $\mathrm{CA}$ ), myelin oligodendrocyte glycoprotein (MOG) (mouse; kind gift from C. Linington, University of Aberdeen, Aberdeen, UK), TGF $\beta$ receptor II (rabbit; Santa Cruz Biotechnology, Santa Cruz, CA), and p-Smad2/3 (rabbit; Cell Signaling Technology). Antibodies were diluted in $0.1 \mathrm{M}$ PBS (0.5\% Triton X-100, 10\% normal serum). Appropriate species/subclass-specific secondary antibodies conjugated to FITC, TRITC (1:200; Jackson ImmunoResearch, West Grove, PA), or biotin (1:200; Vector Laboratories, Burlingame, CA), or the tyramide signal amplification kit (PerkinElmer, Wellesley, MA) were used for additional detection and stainings were analyzed at a Olympus (Tokyo, Japan) FV1000 laser-scanning confocal microscope with optical sections of 1 $\mu \mathrm{m}$ intervals.

For detection of proliferating cells, the DNA base analog BrdU (Sigma) was injected intraperitoneally (100 mg/kg body weight) $1 \mathrm{~h}$ before perfusion to label fast proliferating cells (short pulse). To label slow dividing stem cells, BrdU was given in the drinking water $(1 \mathrm{mg} / \mathrm{ml})$ for 2 weeks followed by another 2 weeks with BrdU-free drinking water. Terminal deoxynucleotidyl transferase-mediated biotinylated UTP nick end labeling (TUNEL) staining was done using the cell death kit (Roche, Indianapolis, IN).

In situ hybridization. Mouse cDNAs of BMP ligands (kind gift from B. L. M. Hogan, Duke University Medical Center, Durham, NC), Noggin (kind gift from R. M. Harland, University of California, Berkeley, CA), BMPRII (kind gift from M. Ruat, Neurobiology Institute Alfred Fessard, Gif-sur-Yvette, France), Smad4 (kind gift from Y. Chai, University of
Southern California, Los Angeles, CA), and Ids (kind gift from K. Miyazono, University of Tokyo, Tokyo, Japan) are used as templates for in situ hybridization probes. Smad4 probe binds to a region corresponding exon 6-10 of transcript. Digoxigenin-labeled RNA probes were synthesized by in vitro transcription using the NTP labeling mix from Roche and T3, T7, or SP6 polymerase from Stratagene (La Jolla, CA). In situ hybridizations were performed on $20-\mu$ m-thick cyrostat sections with hybridization buffer containing $0.5 \%$ CHAPS (3-[(3-cholamidopropyl)dimethylammonio]-1-propanesulfonic acid) according to standard protocols. Fluorescent in situ hybridization was performed with HNPP fluorescent detection set (Roche).

Noggin infusion. Noggin (Peprotech, Rocky Hill, NJ) dissolved in artificial CSF (aCSF) or aCSF only was infused at a rate of $500 \mathrm{ng} / \mathrm{d}$ for $7 \mathrm{~d}$ into the lateral ventricle of C57BL/6/J mice at the coordinates -0.2 (anterioposterior), 1 (mediolateral), 2 (dorsoventral) by osmotic minipumps ( $1 \mu \mathrm{l} / \mathrm{h}$ ALZET osmotic minipumps 2001; Sigma; Brain Infusion Kit II; Sigma). Animals were killed $3 \mathrm{~d}$ after Noggin infusion.

Viral vectors and stereotaxic injections. Murine leukemia virus (MLV)derived retrovirus pseudotyped with the VSV-G (vesicular stomatitis virus glycoprotein) expressing either green fluorescent protein (GFP) or Cre recombinase were prepared as previously described (Hack et al., 2005). CMV (cytomegalovirus) promoter containing lentiviral vectors expressing either GFP (LV-GFP) or Cre (LV-Cre) are based on a previously described vector system (Pfeifer et al., 2001) and were produced as described previously (Pfeifer et al., 2002). For stereotaxic injections, mice were anesthetized (ketamine, $100 \mathrm{mg} / \mathrm{kg}$, ketavet; Amersham Biosciences, Erlangen, Germany; and xylazine, $5 \mathrm{mg} / \mathrm{kg}$, Rompun; Bayer, Leverkusen, Germany) injected with $1 \mu \mathrm{l}$ of viral suspension at the coordinates 0.6 (anterioposterior), 1.2 (mediolateral), and 2-1.7 (dorsoventral) relative to bregma (Saghatelyan et al., 2004) for SEZ. For additional details, see Buffo et al. (2005) and Hack et al. (2005); and for coordinates for corpus callosum (CC) injections, see Menn et al. (2006).

Transplantation. For transplantation experiments Myristoyl (myr)Venus animals were used. In this mouse line, Venus protein is fused with Myristoyl protein, which is a lipid-modified protein present in plasma membrane of all cells (Rhee et al., 2006). SEZ of 6-week-old myr-Venus animals were dissected and prepared for transplantation as described previously (Seidenfaden et al., 2006; Berninger et al., 2007). A total of 30,000 cells was transplanted into the SEZ at the coordinates described above. Venus protein was detected with GFP antibody.

Quantitative analysis. Quantifications (absolute cell numbers, marker coexpression) were performed by means of Neurolucida connected to an Axiophot Zeiss (Oberkochen, Germany) microscope ( $40 \times$ objective). The analysis was performed on sagittal sections at mediolateral levels from 0.6 to $1 \mathrm{~mm}$ relative to midline (three to seven sections per animal). The SEZ area analyzed was $60,000 \mu \mathrm{m}^{2}$ limited to $50-100 \mu \mathrm{m}$ away from the ependymal cell layer, which is corresponding to almost whole SEZ at those levels. Statistical analysis was performed by unpaired Student's $t$ test, and all numbers were expressed as mean \pm SEM.

\section{Results}

Activity of BMP-mediated signaling in adult neural stem cells of the SEZ, but not SGZ

Consistent with previous data ( $\operatorname{Lim}$ et al., 2000; Peretto et al., 2002, 2004; Fan et al., 2003), we noted the local enrichment of several components of the BMP pathway along the lateral wall of the lateral ventricle (Fig. $1 A-G$ ). These include mRNA transcripts of the BMP ligands 2, 4, 6, and 7 (Fig. 1A-D), the feedback inhibitor Noggin (Fig. $1 E$ ), the BMP-specific type II receptor (BMPRII) (Fig. $1 F$ ), the transcription factor Smad4 that mediates BMP signaling (Fig. 1G), and Id1 and -3 (Fig. $1 H$ ) (data not shown), which act as downstream targets of the BMP pathway. This expression pattern prompted us to examine whether BMPmediated signaling activity can be detected in the adult SEZ. Because the receptor Smads 1, 5, and 8 are specifically phosphorylated and translocated to the nucleus after heterodimerization with Smad4 on BMP binding to the receptor dimer (Wrana, 
2000; Shi and Massague, 2003), we monitored BMP activity by immunostaining for the phosphorylated forms of Smads 1, 5, and 8 (p-Smad1/5/8). Indeed, many p-Smad1/5/8-positive (p-Smad1/5/8+) nuclei were detected along the lateral wall of the lateral ventricle (Fig. $1 \mathrm{I}-\mathrm{O}$ ), indicating active BMP signaling in this zone. In contrast, we hardly observed $\mathrm{p}-\mathrm{Smad} 1 / 5 / 8$ immunoreactivity in the adult SGZ, whereas pyramidal neurons in the CA regions were positive (supplemental Fig. $1 A$, available at www.jneurosci.org as supplemental material). Similarly, p-Smad1/5/8 immunostaining was detectable in some neuronal populations in the forebrain, but not in parenchymal glia (data not shown) (for Smad4, see supplemental Fig. $1 H, H^{\prime}$, available at www.jneurosci.org as supplemental material). Thus, outside the SEZ, p-Smad 1,5,8 immunoreactivity was mostly restricted to postmitotic neurons.

In contrast, within the SEZ, the majority of p-Smad $1 / 5 / 8+$ cells (60\%) were astrocytes $($ GFAP +$)$ (Fig. $1 I, N, P)$. To determine whether the p-Smad1/5/8+ astrocytes $(\mathrm{GFAP}+)$ contain self-renewing stem cells, we used a label-retaining protocol. Addition of the DNA-base analog BrdU for 2 weeks to the drinking water followed by 2 weeks without BrdU allows labeling slow-dividing cells that maintain BrdU in contrast to the fastproliferating TAPs that dilute the BrdU in further cell divisions that they undergo during the 2 weeks when no BrdU was added to the drinking water. In addition to labeling the slow-dividing stem cells, this protocol also labels any cells that leave the cell cycle shortly after incorporating BrdU, such as newly generated DCX + neuroblasts (30\% of BrdUretaining cells are $\mathrm{DCX}+)$. Although the BrdU-retaining postmitotic neuroblasts were not $\mathrm{p}-\mathrm{Smad} 1 / 5 / 8+, 43 \%(n=48$ cells $)$ of the remaining BrdU-retaining cells expressed p-Smad1/5/8 (Fig. 1O), suggesting that a high fraction of slow-dividing stem cells is subject to BMP signaling. To further ensure the identity of these cells as stem cells, we stained for PDGFR $\alpha$ as a marker for the stem cell subset among SEZ astrocytes (Jackson et al., 2006). Indeed, these cells were subject to BMP signaling as observed by p-Smad1,5,8 immunoreactivity (data not shown) or by GFP expression in a BMP reporter mouse line (supplemental Fig. $1 D-D^{\prime \prime \prime}$, available at www.jneurosci.org as supplemental material). In this mouse line, GFP is expressed under the control of the BMP-specific responsive element (BRE) containing Smad 1 and 5 binding sites derived from the Id 1 promoter (Monteiro, Chuva da Sousa Lopes, Mummery, unpublished observations). Consistent with the localization of $\mathrm{p}-\mathrm{Smad} 1 /$ $5 / 8$, GFP colocalized with GFAP, but not with DCX in the adult SEZ of the BRE-GFP mice (supplemental Fig. $1 B-B^{\prime \prime}, C$, available at www.jneurosci.org as supplemental material). Thus, the Smad-mediated BMP-signaling pathway is active in stem cells of the adult SEZ, but not in neuroblasts.
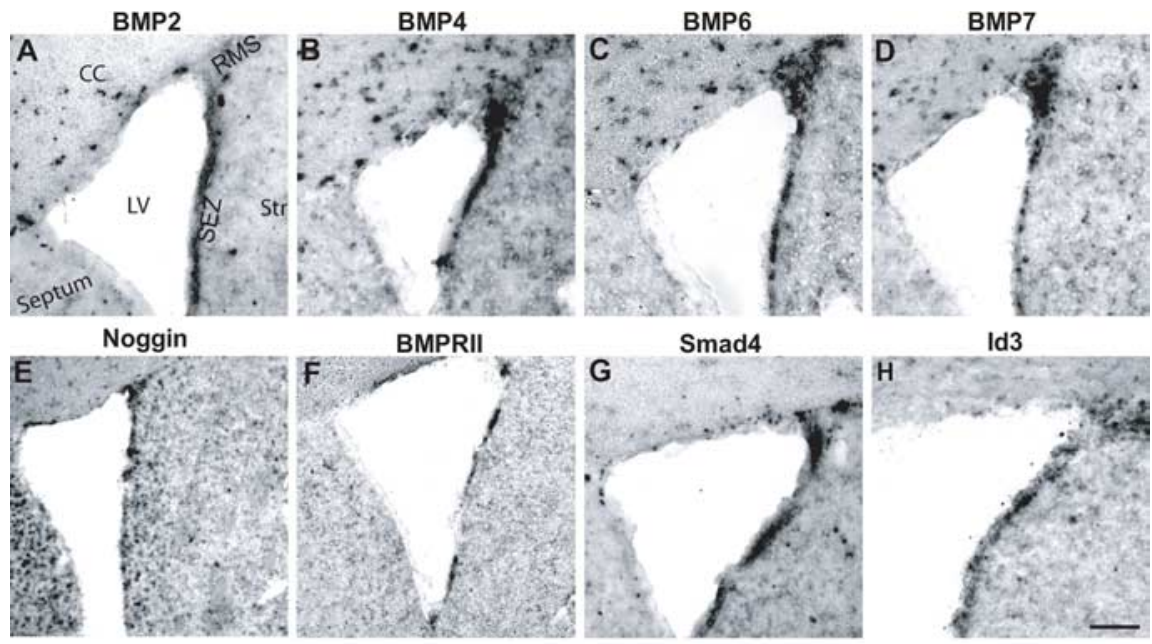

Smad4

Id3
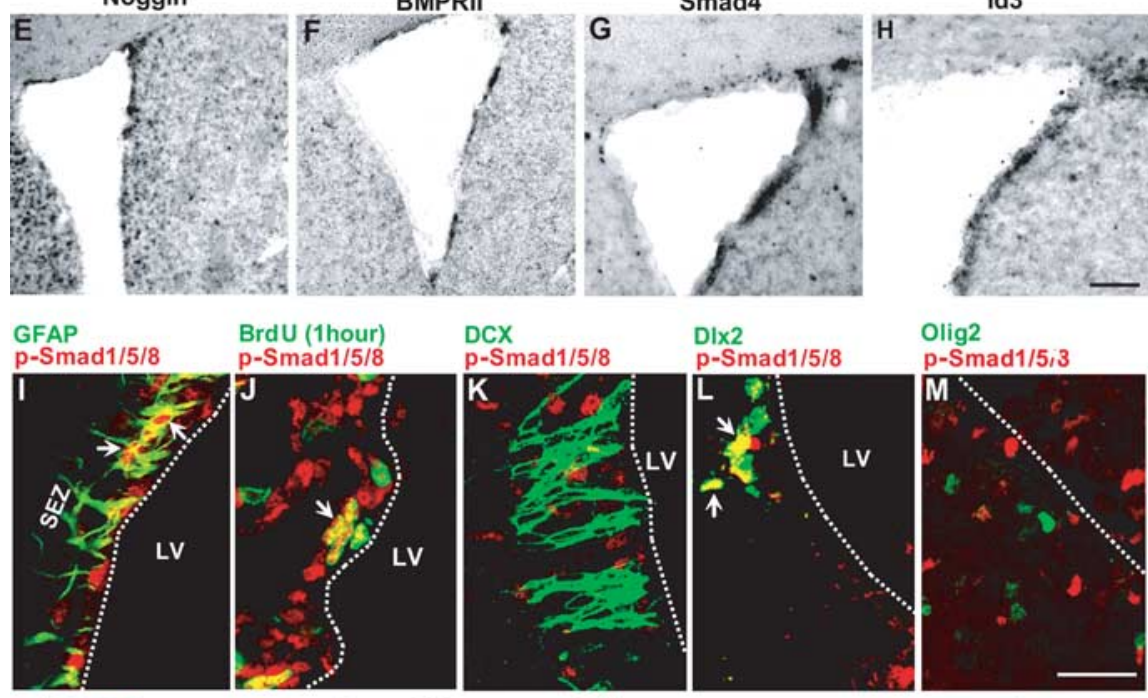

Dix2

p-Smad1/5/8

Olig2
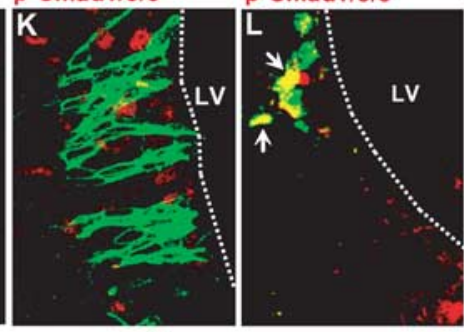

-Smad1/5i3

M
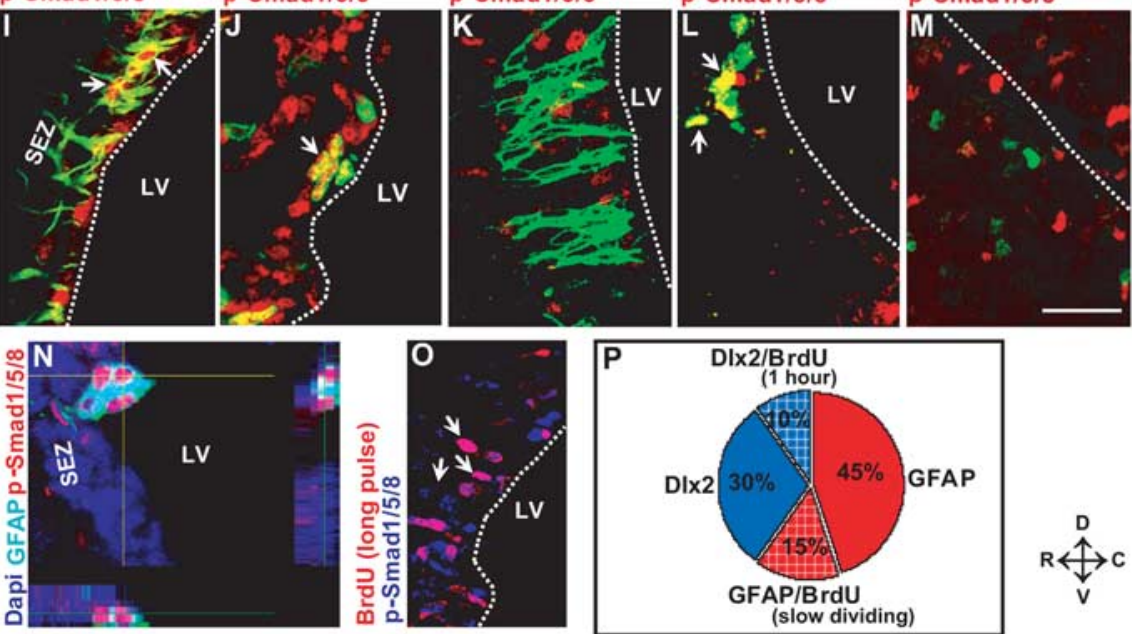

Figure 1. Expression and functional activity of BMP signaling components in the adult SEZ. $\boldsymbol{A}-\boldsymbol{H}$, In situ hybridization of mRNA transcripts of BMP ligands $(\boldsymbol{A}-\boldsymbol{D})$, the extracellular inhibitor noggin $(\boldsymbol{E})$, BMP receptor II $(\boldsymbol{F})$, the central signaling mediator $S$ mad phosphorylated Smads 1/5/8 (p-Smad1/5/8) with different cell type-specific antigens in the adult SEZ as indicated in the panels. PrdU + cells $(J)$, but not in DCX + neuroblasts $(K)$. p-Smad1/5/8 also colocalizes with the transcription factor Dlx 2

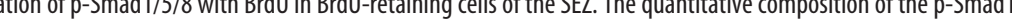

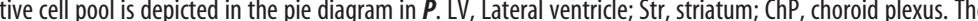
Scale bars: (in $\boldsymbol{H}$ ) $\boldsymbol{A}-\boldsymbol{H}, 100 \mu \mathrm{m}$; (in $\boldsymbol{M}$ ) $\boldsymbol{I}-\mathbf{0}, 70 \mu \mathrm{m}$.

The remaining (DCX- and GFAP-negative) population is mostly composed of TAPs that express transcription factors of the Dlx family (Doetsch et al., 2002). Indeed, all DCX- and GFAP-negative $\mathrm{p}$-Smad1/5/8+ cells were Dlx2-immunoreactive (Fig. $1 L, P$ ). In contrast, $\mathrm{p}-\mathrm{Smad} 1 / 5 / 8$ immunoreactivity did not colocalize with the transcription factor Olig2 (Fig. $1 M$ ) expressed by a subset of TAPs (Hack et al., 2005; Menn et al., 2006). Thus, p-Smad1/5/8 + cells responding to BMP signaling in the adult SEZ are composed of $60 \%$ of astrocytes and slow-dividing stem cells and $40 \%$ of Dlx2+ TAPs (Fig. $1 P$ ).

\section{Conditional deletion of Smad4 in the adult SEZ}

To understand the role of BMP signaling in the adult SEZ, we used first a genetic approach by conditionally deleting Smad4, the common mediator of BMP and TGF $\beta$ signaling. To ensure Smad4 expression in the cells found to be responsive to BMP, we 
examined Smad4 mRNA by fluorescent in situ hybridization. Indeed, also Smad4 transcripts colocalized with GFAP in the adult SEZ, but not in other brain regions (supplemental Fig. $1 E-H^{\prime}$, available at www.jneurosci.org as supplemental material). This allowed us to take advantage of the GLAST:CreERT2 mouse line (Mori et al., 2006) that expresses the inducible form of Cre in the locus of the astrocyte-specific glutamate transporter (GLAST), permitting the induction of Cre recombinase activity specifically in adult astroglial cells and stem cells by tamoxifen administration. Because Smad4 is not expressed in astrocytes outside the SEZ, GLAST:CreERT2 mediated excision of exon 8 of Smad4 (Smad4fl/fl) (Yang et al., 2002) is specific to the astrocytes and stem cells in the SEZ. Moreover, GLAST is not expressed in other cell types in the SEZ, such as ependymal cells (Mori et al., 2006) (see also below).

When these mouse lines were crossed and tamoxifen was given to adult control littermates with either no (GLAST:CreERT2/Smad4wt/wt) or only a single allele of Smad4 floxed (GLAST:CreERT2/Smad4wt/fl) strong in situ hybridization signal for Smad4 was present in the SEZ (Fig. 2A). In contrast, Smad4 mRNA was virtually undetectable in the SEZ of adult GLAST:CreERT2/Smad4fl/fl mice (referred to as Smad4-/throughout the text) $10 \mathrm{~d}$ after tamoxifen application (Fig. $2 \mathrm{~B}$ ). Because phosphorylated Smads require Smad4 to localize to the nucleus (Wrana, 2000), we checked p-Smad1/5/8 localization $10 \mathrm{~d}$ after tamoxifen application. Indeed, very few $\mathrm{p}-\mathrm{Smad} 1 / 5 / 8+$ nuclei could be detected in the Smad4-/-SEZ in contrast to the many positive nuclei in the controls (Fig. 2C,D). Similarly, GLAST:CreERT2/Smad4fl/fl mice treated with corn oil instead of tamoxifen contained many $\mathrm{p}-\mathrm{Smad} 1 / 5 / 8+$ nuclei in the SEZ similar to GLAST:CreERT2/Smad4wt/fl mice treated with tamoxifen (data not shown). The loss of both the Smad4 in situ signal and the $\mathrm{p}-\mathrm{Smad} 1 / 5 / 8$ immunostaining in tamoxifen-treated GLAST: CreERT2/Smad4fl/fl mice was specific to SEZ astrocyte-derived lineages. Smad 4 mRNA or p-Smad1/5/8 was still present in neurons of the cerebral cortex and the CA3 region of the hippocampus or the choroid plexus (data not shown). Thus, tamoxifeninduced recombination in GLAST + cells very efficiently deleted Smad 4 and interfered with $\mathrm{p}$-Smad1/5/8 translocation to the nuclei in the adult SEZ only.

\section{Smad4 deletion does not affect neural stem cell number and properties, but reduces neurogenesis}

Because Smad4 was deleted in astrocytes, we first examined the astrocytes labeled by GFAP in the adult SEZ in the Smad4-/compared with control mice (Fig. $3 A, B$ ). However, Smad4 deletion had no effect on the number of GFAP+ cells in the SEZ neither at $10 \mathrm{~d}$ after tamoxifen (Fig. $3 E$ ) nor at later stages $(21 \mathrm{~d}$ ) (data not shown). However, many GFAP + cells do not proliferate and Smad4 may act only in the slow-dividing GFAP + cells, the stem cells. We therefore quantified the number of labelretaining BrdU+ (DCX-negative) cells and found it not to be different between the genotypes (supplemental Fig. $2 A-D$, available at www.jneurosci.org as supplemental material). Similarly, no difference in neurosphere formation (primary and secondary, supplemental Fig. 2 E, available at www.jneurosci.org as supplemental material) was observed. Thus, deletion of Smad4 in adult neural stem cells does not interfere with the stem cell number and their self-renewal in vitro or in vivo.

Because p-Smads 1/5/8 and Smad4 (data not shown) were also detected in TAPs, we examined their number by labeling with a $1 \mathrm{~h}$ BrdU pulse (TAPs, BrdU+DCX - cells). Again, no difference was observed between the genotypes in the number of TAPs (Fig.

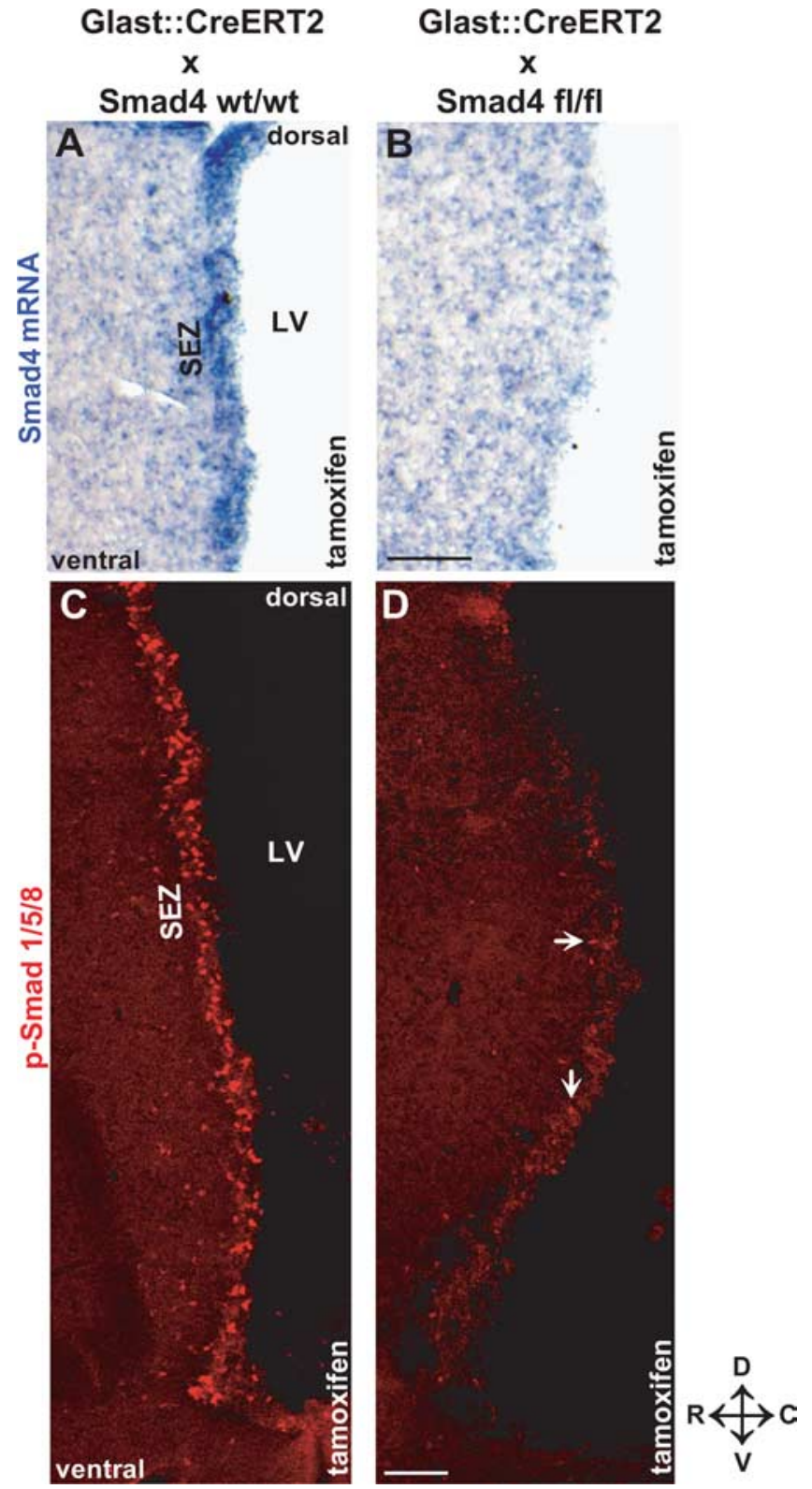

Figure 2. Inducible deletion of Smad4 in adult astrocytes and neural stem cells in the adult SEZ. $\boldsymbol{A}, \boldsymbol{B}$, In situ hybridization of Smad4 mRNA in the adult SEZ $10 \mathrm{~d}$ after activation of (reERT2 expressed in the GLAST locus (GLAST:CreERT2) by tamoxifen in mice without $(\boldsymbol{A})$ or with $(\boldsymbol{B})$ exon 8 of Smad4 flanked by loxP sites. Note the loss of Smad4 mRNA in $\boldsymbol{B}$ versus $\boldsymbol{A}$. $\boldsymbol{C}, \boldsymbol{D}$, Fluorescent micrographs of $\mathrm{p}$-Smad1/5/8 immunostaining in GLAST:CreERT2 mice WT for the Smad4 locus $(\boldsymbol{C})$ or homozygous for the floxed exon 8 of $\operatorname{Smad} 4(\boldsymbol{D}) 10 \mathrm{~d}$ after induction of Cre-mediated recombination by tamoxifen. Note the widespread loss of nuclear localization of $\mathrm{p}$-Smad1/5/8 after deletion of Smad4 (D). The arrows in $\boldsymbol{D}$ indicate some of the remaining $\mathrm{p}$-Smad1/5/8 + cells also demonstrating the same quality of immunostaining. LV, Lateral ventricle; D, dorsal; V, ventral; $R$, rostral; $C$, caudal. Scale bars: (in $\boldsymbol{B}) \boldsymbol{A}, \boldsymbol{B}, 100 \mu \mathrm{m}$; (in D) C, D, 100 $\mu \mathrm{m}$.

$3 E)$. However, the DCX staining applied on these sections revealed a consistent decrease in immunoreactivity in the Smad4-/-SEZ compared with controls (Fig. 3C,D). Indeed, quantification of the number of DCX + cells in the SEZ revealed a reduction to one-half of the control values (Fig. $3 E$ ). Notably, also GLAST:CreERT2/Smad4fl/fl animals that were treated with corn oil instead of tamoxifen did not show a reduction in neurogenesis (three animals). To follow recombined cells after Smad4 deletion, we crossed GLAST:CreERT2/Smad4fl mice with the 

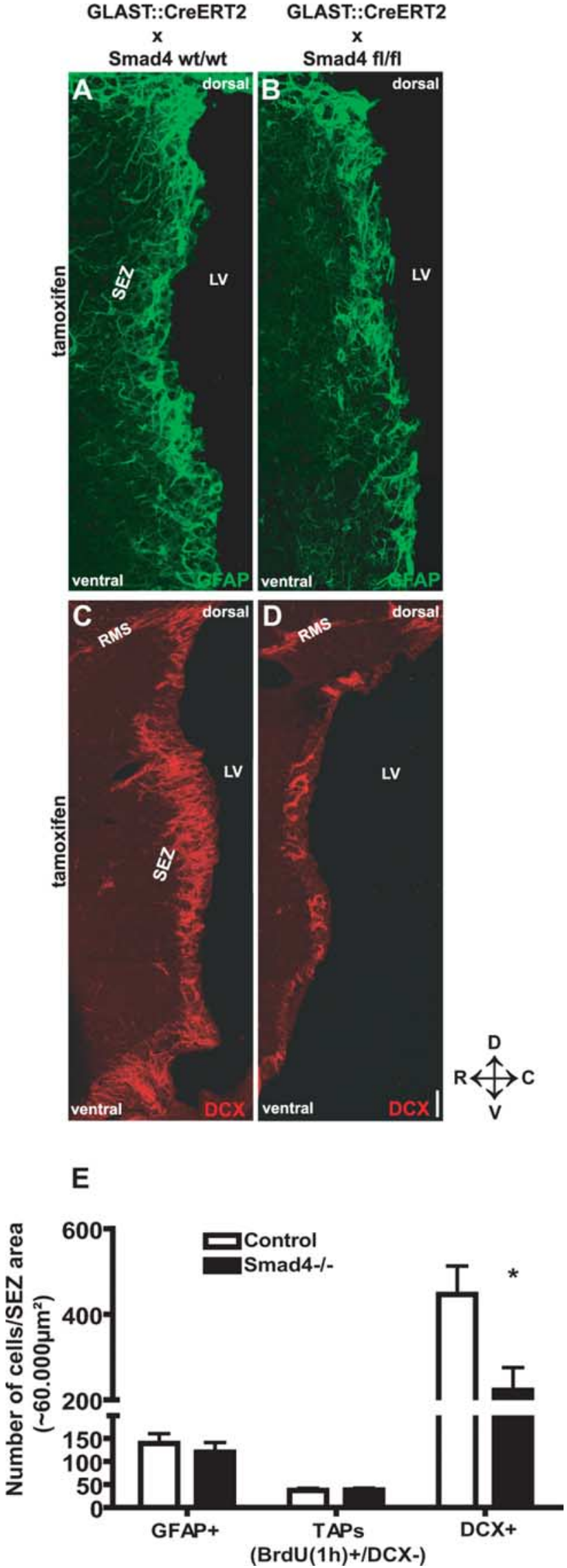

Figure 3. Cell fate analysis after deletion of Smad4 in the adult SEZ. $A-D$, Fluorescent micrographs depicting GFAP immunostaining for astrocytes and stem cells $(\boldsymbol{A}, \boldsymbol{B})$ and DCX immunostaining for neuroblasts $(\boldsymbol{C}, \boldsymbol{D})$ in the adult SEZ $10 \mathrm{~d}$ after induction of Cre-mediated recom-
ROSA26 reporter line (R26R) (Soriano, 1999) in which LacZ expression is initiated on Cre-mediated recombination and the progeny of the recombined cells can be traced. The same results, namely a reduction in the number of DCX + , but not TAPs and GFAP + cells, were observed for reporter + cells in the SEZ of GLAST:CreERT2/Smad4fl/fl/ROSA26 mice (supplemental Fig. 3 , available at www.jneurosci.org as supplemental material). Thus, the similar numbers of TAPs and GFAP + cells cannot be explained by a compensatory increase in the number of WT cells at the expense of mutant cells. Rather, these results suggest that deletion of Smad4 does not affect stem cell numbers and properties, but strongly affects neurogenesis.

\section{Deletion of Smad4 alters TAP identity by aberrant expression of Olig2}

To understand how neurogenesis is reduced on Smad4 deletion, we first examined whether neuroblasts may die. However, the number of Tunel+ cells was not different in the Smad4-/- or control SEZ $10 \mathrm{~d}$ after tamoxifen application [control, $1.8 \pm 0.8$; Smad4-/-, $1.4 \pm 0.4$ (per SEZ area, see Materials and Methods); three animals each), suggesting that the reduction in neuroblasts is not because of cell death. The reduction in DCX + cells seems also not attributable to defects in neuroblast proliferation because a similar proportion of DCX + cells incorporated BrdU (short pulse) in control and Smad4 $-/-$ mice [percentage DCX of control, $10 \pm 1 \% ; n$ (cells) $=729 ; \operatorname{Smad} 4-/-, 9 \pm 1 \% ; n$ (cells) $=534$; three animals each]. These data therefore suggest that the decrease in neuroblast number on Smad4 deletion may be caused at earlier stages in the lineage, consistent with the localization of $\mathrm{p}$-Smad1/5/8 in cells of earlier lineage stages.

Because the above results also demonstrated normal stem cell numbers and self-renewal as well as normal numbers of TAPs, we hypothesized that the molecular identity of TAPs may be altered in a way to interfere with their progression toward the neuroblast fate. Indeed, immunostaining for Olig2 revealed a prominent increase in the number of Olig2 + cells in the SEZ of Smad4-/mice to double the number in control mice (Fig. $4 B, E, G$ ). Because the total number of TAPs was not increased (Fig. $3 E$ ), the upregulation of Olig2 either occurs within the TAP population or ectopically in astrocytes or neuroblasts. However, virtually no colocalization of Olig2 and GFAP or DCX was detectable in the Smad4-/- SEZ (data not shown). Instead, Olig2 was frequently found colocalized with Dlx2 in the Smad4-/-SEZ, which was never observed in the SEZ of control mice (Fig. 4C, F, G). Because Olig2 overexpression was previously shown to interfere with neurogenesis in the adult SEZ (Hack et al., 2005), we examined whether upregulation of Olig2 in Dlx2 + cells may divert these from their normal neurogenic lineage. Dlx2+ cells normally comprise $\sim 70 \%$ DCX + neuroblasts and 30\% DCX-negative TAPs (Fig. $4 A, H$ ). However, $10 \mathrm{~d}$ after Smad4 deletion, the $\mathrm{DCX}+$ neuroblast population among Dlx2+ cells was reduced, leading to a reduction in the total number of Dlx2+ cells (Fig. $4 D, H)$. However, among Dlx2+ cells, the DCX-negative frac-

bination. $\boldsymbol{E}$, Histogram depicting the number of GFAP-immunopositive astrocytes and stem cells $[n$ (cells) $=2922$ (control), 2531 (Smad4-/-); 4 animals each], the number of TAPs $($ BrdU,$+ D C X-)$ labeled with BrdU $1 \mathrm{~h}$ before kill $[n$ (cells) $=240$ (control), 426 (Smad4 - / $-) ; 3$ animals each] and the number of DCX + neuroblasts $[n$ (cells) $=11,752$ (control), 5400 (Smad4-/-); 4 animals each] $10 \mathrm{~d}$ after tamoxifen application. Note the significant reduction of neuroblasts, but not TAPs and GFAP + cells $10 \mathrm{~d}$ after Smad4 deletion. Error bars indicate SEM. * $p<0.05$. LV, Lateral ventricle. Scale bar: (in $\boldsymbol{D}) \boldsymbol{A}, \boldsymbol{B}, 75 \mu \mathrm{m} ; \boldsymbol{C}, \boldsymbol{D}, 100 \mu \mathrm{m}$. SEZ area indicates $60,000 \mu \mathrm{m}^{2}$ (see also Materials and Methods). 

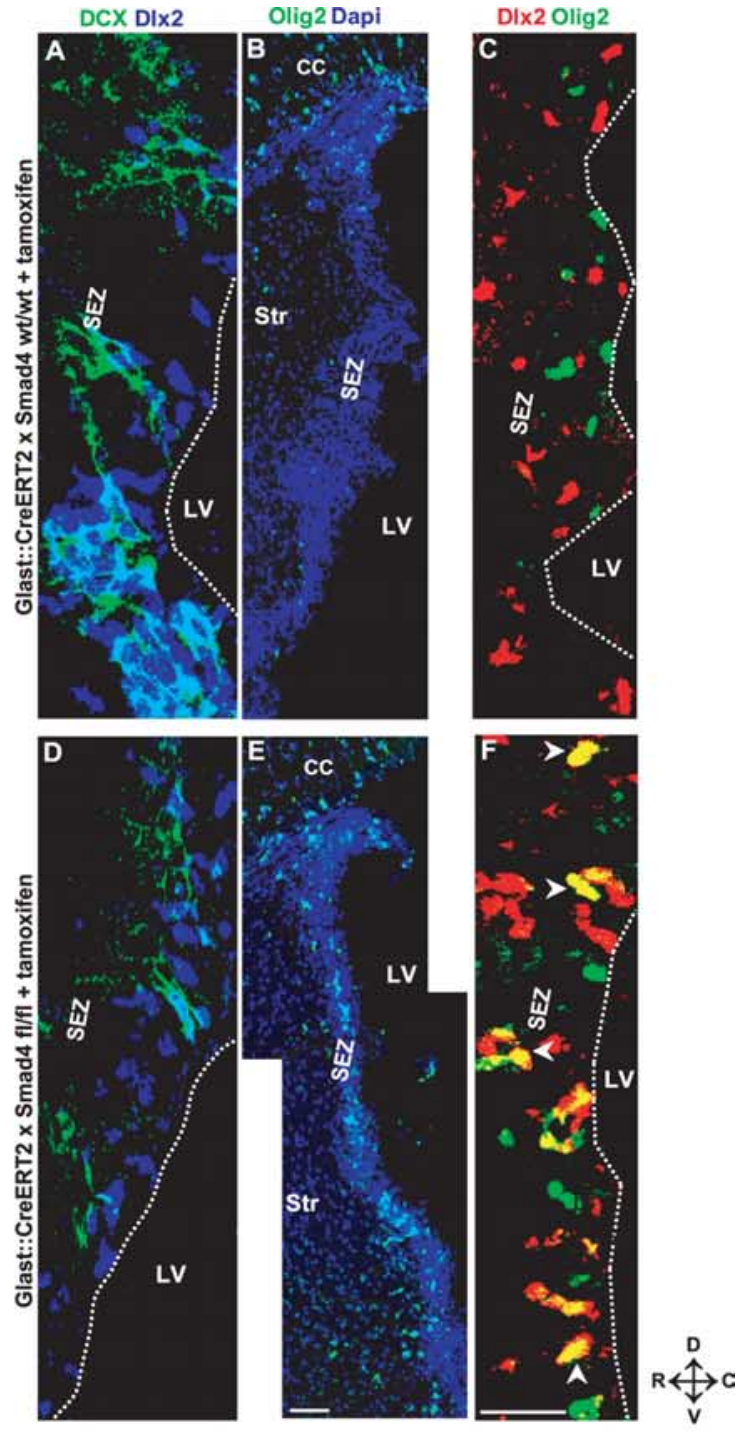

\section{G}

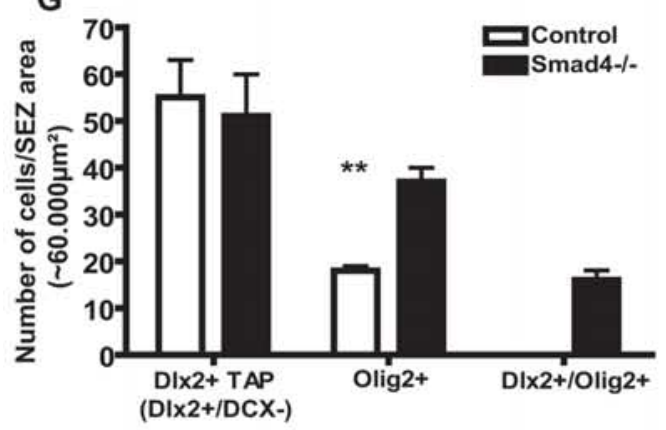

H

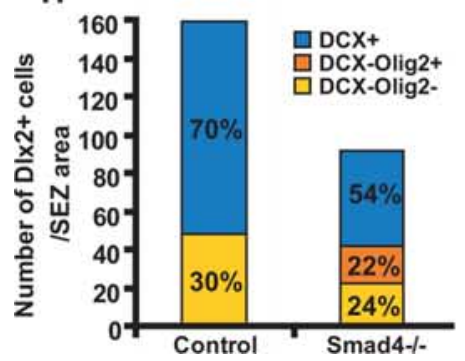

Figure 4. Alteration of transit-amplifying precursor fate on Smad4 deletion. $\boldsymbol{A}-\boldsymbol{F}$, Fluorescence micrographs depicting $D C X$ and DlX2 double staining $(\boldsymbol{A}, \boldsymbol{D})$, 0 lig2 immunostaining $(\boldsymbol{B}, \boldsymbol{E})$, and Dlx2/0lig2 double stainings $(\boldsymbol{C}, \boldsymbol{F})$ (double-positive nuclei are indicated by arrowheads) in tion increased to $46 \%$ (Fig. $4 H$ ). Interestingly, the nonneuroblast fraction was mostly composed of Dlx2/ Olig2-double + cells (Fig. 4H), consistent with the notion that the aberrant expression of Olig2 may interfere with the progression toward the neuroblast stage (Hack et al., 2005).

\section{Deletion of Smad4 results in migration of cells to the corpus} callosum and increased oligodendrogliogenesis

Because Olig2 + cells normally migrate from the SEZ to the CC (Menn et al., 2006) and Olig2 overexpression results in a strong increase in the number of cells migrating to the CC (Hack et al., 2005), we hypothesized that the TAPs misspecified after Smad4 deletion may also leave the SEZ and head toward the CC. To test this possibility, we injected retroviral vectors containing GFP into the SEZ of GLAST:CreERT2/Smad4fl/fl or control mice $10 \mathrm{~d}$ after the end of tamoxifen application and examined the location of GFP + cells $10 \mathrm{~d}$ later $(20 \mathrm{~d}$ after the end of tamoxifen application). In control mice, only $2 \%$ of GFP-labeled cells migrated from the SEZ to the CC (Fig. 5A-C), consistent with previous observations (Hack et al., 2005; Menn et al., 2006). However, up to $30 \%$ of all cells labeled by injection into the Smad $4-/-$ SEZ were located in the CC $10 \mathrm{~d}$ later (Fig. 5A-C) (for control experiments assessing the behavior of cells labeled along the injection track, see supplemental Fig. 4, available at www.jneurosci.org as supplemental material). These results thus demonstrate that many more cells originating in the SEZ migrate far into the CC on Smad4 deletion in adult neural stem cells. To assess the fate of the GFP + cells that had migrated from the SEZ into the CC, we stained for PDGFR $\alpha$ to detect immature oligodendrocyte progenitors and $\mathrm{CC} 1$ or $\mathrm{CNPase}$ for oligodendrocytes at later stages. Indeed, most of the GFP + cells in the CC were PDGFR $\alpha+(80 \%)$ (Fig. $5 D, F$ ) and $\sim 60 \%$ were $\mathrm{CC} 1+$, consistent with their progression along the oligodendroglial lineage. To assess the additional maturation of cells that migrated from the SEZ to the CC, we analyzed the brains at later stages after viral vector injection $(21-30 \mathrm{~d})$ (Fig. $\left.5 G-H^{\prime \prime}\right)$. Most cells labeled with GFP virus in the SEZ that had migrated into the CC exhibited additional mature features of oligodendrocytes in regard to their morphology (Fig. $5 G$ ) and the expression of MOG (Fig. $5 H-H^{\prime \prime}$ ), a protein contained only in mature oligodendrocytes. Thus, a large proportion of TAPs upregulate Olig2 after Smad4 deletion and then give rise to cells migrating to the $\mathrm{CC}$ and differentiating into oligodendrocytes rather than generating neuroblasts migrating to the $\mathrm{OB}$.

This phenotype may obviously depend on Olig2 upregulation, because Olig2 was previously shown to direct SEZ cells toward the generation of cells migrating toward the CC (Hack et al., 2005). However, Smad4 deletion may result in deregulation of many other direct or indirect downstream targets in addition to Olig2. We therefore asked whether the upregulation of Olig2 is

the adult SEZ of GLAST:CreERT2 mice without $(\boldsymbol{A}-\boldsymbol{C})$ or with $(\boldsymbol{D}-\boldsymbol{F})$ floxed exon 8 of Smad4 $10 \mathrm{~d}$ after tamoxifen application. $\boldsymbol{G}, \boldsymbol{H}$, Histograms depicting the number of Dlx2+ TAPs $(D \mid x 2+D C X-)(G)[n$ (cells) $=652$ (control), 562 (Smad4- $-1-) ; 3$ animals each], the number of 0lig2 + cells (G) $[n$ (cells) $=255$ (control), 513 (Smad4-/-); 3 animals each], and the number of Olig2- and Dlx2-double-positive cells $(\boldsymbol{G})[n$ (cells) $=107 ; 3$ animals each] or the number of all Dlx2 + cells $(\boldsymbol{H})[n$ (cells) $=1430$ (control), 834 (Smad4-/ $)$ ); 3 animals each] with the percentage of DCX - or Olig2 + colocalization in the adult SEZ of GLAST:CreERT2 without (control) or with floxed exon 8 of Smad4 (Smad4-/-) $10 \mathrm{~d}$ after tamoxifen application. Note the increase in 0 lig2 expression in the $D \mid x 2+D C X$ - population and corresponding decrease in the fraction of $D \mid x 2+D C X+$. Error bars indicate $S E M .{ }^{* *} p<0.01$. The dashed white line in $\boldsymbol{A}, \boldsymbol{C}, \boldsymbol{D}$, and $\boldsymbol{F}$ depicts the ventricular surface of the SEZ. LV, Lateral ventricle; Str, striatum; $D$, dorsal; $V$, ventral; $R$, rostral; $C$, caudal. Scale bars: (in $E) B-E, 100 \mu \mathrm{m}$; (in $\boldsymbol{F}) \boldsymbol{A}, \boldsymbol{C}, \boldsymbol{D}, \boldsymbol{F}, 60 \mu \mathrm{m}$. 
really the key factor for this lineage diversion by attempting a rescue via suppression of Olig2 function. The fusion of Olig2 to the strong activator VP16 has previously been shown to antagonize the endogenous function of Olig2 that acts as a repressor (Mizuguchi et al., 2001; Buffo et al., 2005; Hack et al., 2005). We therefore injected a previously described virus containing Olig2VP16, IRES, and GFP (Mizuguchi et al., 2001; Buffo et al., 2005; Hack et al., 2005) into the SEZ of Smad4-/ - mice (tamoxifen was applied $10 \mathrm{~d}$ before virus injection as above). The proportion of Olig2VP16 transduced cells migrating to the CC was significantly reduced compared with the cells infected with a control virus in Smad4-/- mice (Fig. 5C). Even more strikingly, the proportion of Olig2VP16$\mathrm{GFP}+$ cells migrating via the rostral migratory stream (RMS) to the olfactory bulb (OB) was increased to normal wild-type (WT) levels as observed on GFP virus injection into control mice (Fig. 5C). Thus, suppression of Olig2 function achieves a rather complete rescue of the defective neurogenesis on Smad4 deletion.

WT cells transplanted into the Smad4-/SEZ are not impaired in neurogenesis Because deletion of Smad4 in all astrocytes of adult SEZ may change the niche signals and thereby contribute to the defects in neurogenesis, we examined the function of the neurogenic niche by transplanting a small number of WT cells into 6-week-old control and Smad4 $-/-$ mice (Fig. 6A). Toward this aim, adult SEZ cells were isolated from 6-week-old animals expressing the green fluorescent protein Venus targeted to the plasma membrane ubiquitously (Rhee et al., 2006). A total of 30,000 cells was transplanted into the SEZ of control or Smad4 $-/-$ mice $10 \mathrm{~d}$ after the end of tamoxifen application. Notably, at this time point neurogenesis was decreased and Olig2 expression was increased in the Smad4-/- mice (Figs. 3, 4). Consistent with our aim to expose WT cells to a mutant environment, in most cases only a single Venus + cell was detected in each section $7 \mathrm{~d}$ after transplantation. When we examined the identity of the transplanted Venus + cells (Venus protein is detected by GFP antibody) in the SEZ, RMS, and OB, most of them were DCX + neuroblasts, in both a control or Smad4- / - SEZ environment (Fig. 6B,C) [percentage of DCX+ cells: $80 \pm 2 \%$, control ( 44 cells); $78 \pm 5 \%$, Smad4 $-/-(71$ cells); two animals each].

Because even specified neuroblasts change their fate toward a non-neurogenic lineage on transplantation at positions outside the SEZ (Seidenfaden et al., 2006), we conclude from our trans-
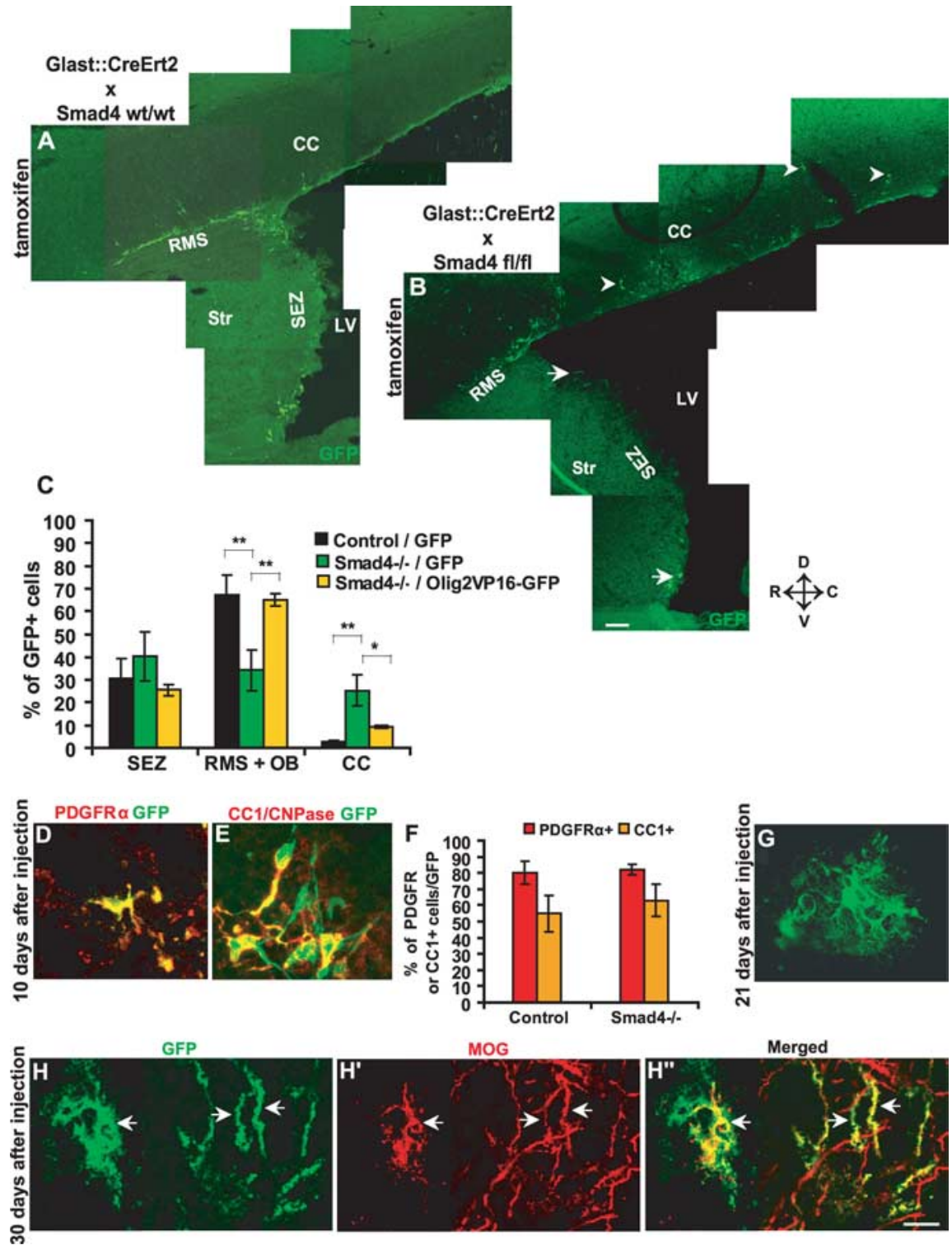

Figure 5. Smad4 deletion results in increased migration of SEZ-derived cells toward the corpus callosum and the generation of mature oligodendrocytes. $A, B$, Fluorescent micrographs depicting the location of GFP + cells $10 \mathrm{~d}$ after GFP-virus injection into the SEZ of GLAST:CreERT2 without $(\boldsymbol{A})$ or with $(\boldsymbol{B})$ floxed exon 8 of Smad4 $10 \mathrm{~d}$ after tamoxifen application. The arrowheads indicate GFP + cells located in the CC. The arrow in $\boldsymbol{B}$ highlights the small number of GFP + cells remaining in the SEZ after Smad4 deletion. C, Histogram depicting the percentage of GFP + cells located in the SEZ, RMS, OB, and CC 10 d after injection into the SEZ of GLAST:CreERT2 without [control, $n$ (animals) $=3 ; n$ (cells) $=1404$ ] or with floxed exon 8 of Smad4 [Smad4-/,$n$ (animals) $=3 ; n$ (cells) $=440] 10 \mathrm{~d}$ after tamoxifen application. Note the increase of GFP-labeled cells in the CC and the corresponding decrease of GFP-labeled cells in the OB on Smad4 deletion. The third bar represents Olig2VP16-GFP injection into SEZ of GLAST:CreERT2 with floxed exon 8 of Smad4 [ $n$ (cells) $=528 ; 2$ animals]. Note that the interference with 0lig2 function fully rescues the generation of neuroblasts migrating via RMS to the OB in Smad4-/- mice. Error bars indicate SEM. $\boldsymbol{D}, \boldsymbol{E}$, Fluorescent micrographs of GFP + cells in CC expressing immature (PDGFR $\alpha)(\boldsymbol{D})$ and partially mature (CC1 and/or CNPase) (E) oligodendrocyte markers. $\boldsymbol{F}$, Histogram depicting the proportion of PDGFR $\alpha-$ or CC1 - and/or CNPase + cells among the GFP + cells labeled in the SEZ that then migrated into the CC. Note that virtually all the increased number of cells migrated into the CC in the Smad4- / - differentiated along the oligodendroglial lineage. G, Fluorescent micrograph depicting the morphology of GFP + cells in CC $21 \mathrm{~d}$ after virus injection in the SEZ of Smad4-/-. $\boldsymbol{H}-\boldsymbol{H}^{\prime \prime}$, Fluorescent micrographs of GFP + cells expressing MOG, one of the mature oligodendrocyte marker, in CC of Smad4- / - mice $30 \mathrm{~d}$ after virus injection into the SEZ. The arrows in $\boldsymbol{H}-\boldsymbol{H}^{\prime \prime}$ indicate processes positive for both GFP and MOG. ${ }^{*} p<0.05 ;{ }^{* *} p<0.01$. LV, Lateral ventricle; Str, striatum; D, dorsal; V, ventral; R, rostral; C, caudal. Scale bars: (in $\boldsymbol{B}) \boldsymbol{A}, \boldsymbol{B}, 100 \mu \mathrm{m}$; (in $\boldsymbol{H}^{\prime \prime}$ ) $\boldsymbol{D}, \boldsymbol{G}, \boldsymbol{H}-\boldsymbol{H}^{\prime \prime}, 60 \mu \mathrm{m} ; \boldsymbol{E}, 30 \mu \mathrm{m}$. plantation experiments that the environment in the Smad4-/SEZ niche is still sufficient to support neurogenesis. To further ensure this, we transplanted cells isolated from 6-week-old hGFAP-eGFP mice (Nolte et al., 2001). GFP is expressed in astrocytes and stem cells in the adult SEZ and only persists for a 

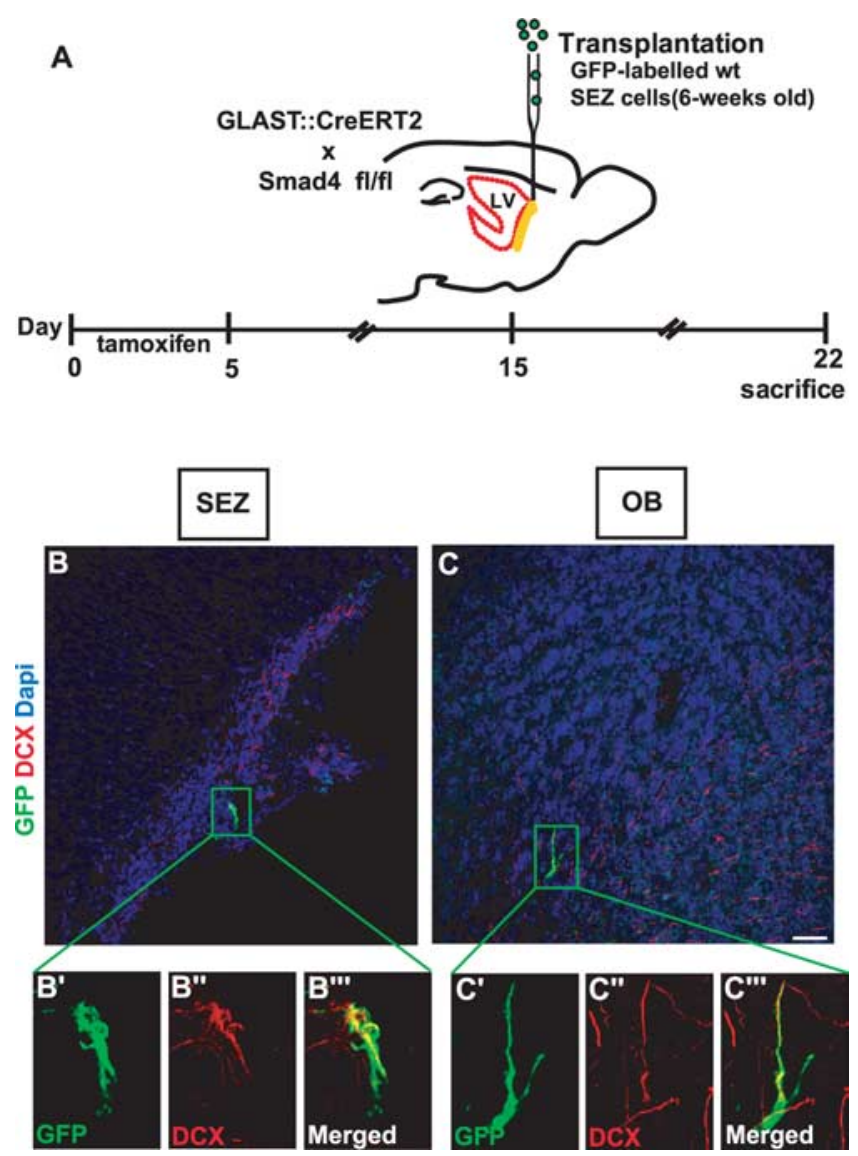

Figure 6. Differentiation of WT cells transplanted into Smad4-/-SEZ. A, Schematic diagram depicting the experimental design of the Venus labeled cells into the SEZ of Glast:CreERT2/ Smad4fl/fl animals. $\boldsymbol{B}-\boldsymbol{C}^{\prime}$, Fluorescent micrographs depicting localization and DCX expression of GFP-labeled cells $7 \mathrm{~d}$ after transplantation in the SEZ $\left(\boldsymbol{B}-\boldsymbol{B}^{\prime \prime \prime}\right)$ and $O B\left(\boldsymbol{C}-\boldsymbol{C}^{\prime \prime}\right)$. Note that GFP-labeled cells generated $D C X+$ neuroblasts and were capable of migrating to the $O B$ after transplantation into the SEZ of Smad4-I-.LV, Lateral ventricle. Scale bar: (in C) B, C, $50 \mu \mathrm{m}$; $B^{\prime}-C^{\prime \prime \prime}, 20 \mu \mathrm{m}$.

short time into their progeny (neuroblasts labeled with BrdU $7 \mathrm{~d}$ before were no longer GFP immunopositive). This implies that GFP + neuroblasts that we detected 1 week after transplantation have been derived within the host environment from stem cells (or some progenitor cells at earlier lineage stages). As we observed indeed $7 \mathrm{~d}$ after transplantation a similar rate of neuroblasts differentiation in both WT and Smad4- - SEZ environment (percentage DCX of GFP + cells: $28 \pm 13 \%$ in WT, $n=157 ; 32 \pm 3 \%$ in Smad4 $-/-, n=198$ ), we conclude that the neurogenic niche in the Smad4- / - SEZ is not altered sufficiently enough, if at all, to impair neurogenesis as WT cells progress normally along their neuronal fate. Thus, Smad4 acts in a cell-autonomous manner to allow neurogenesis by Olig2 suppression.

Smad4 is required at early stages in the stem cell-derived lineage

Because the above results support a cell-autonomous function of Smad4, we next asked at which stage in the neural stem cellderived lineage $\mathrm{Smad} 4$ is required. Toward this end, we deleted Smad4 at different stages in the lineage. To delete Smad4 in all fast-proliferating cells of the SEZ (TAPs and neuroblasts) and spare the stem cells, we targeted Cre by the Moloney-based viral (MLV) vectors that require the breakdown of the nuclear envelope during cell division to incorporate their genome (Fig. 7).
A
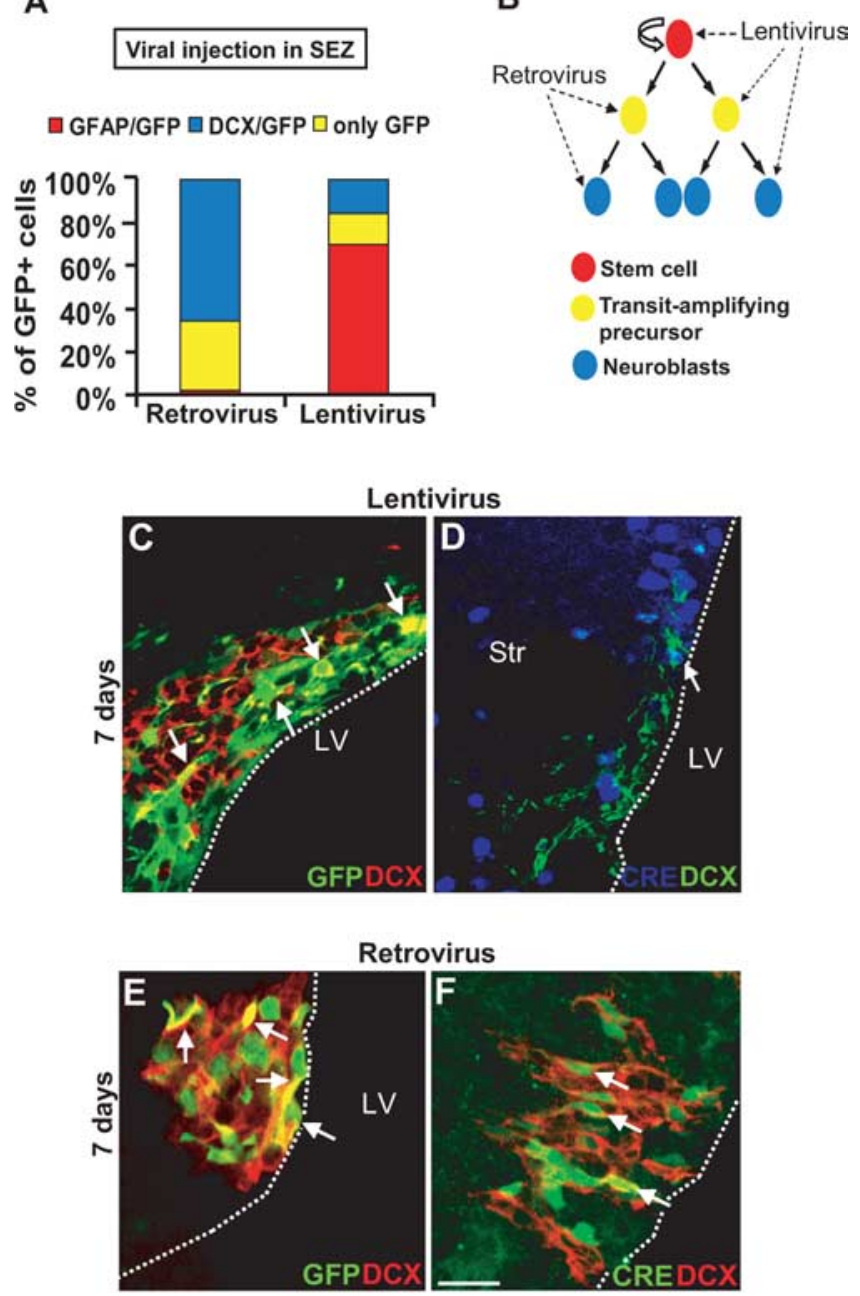

G

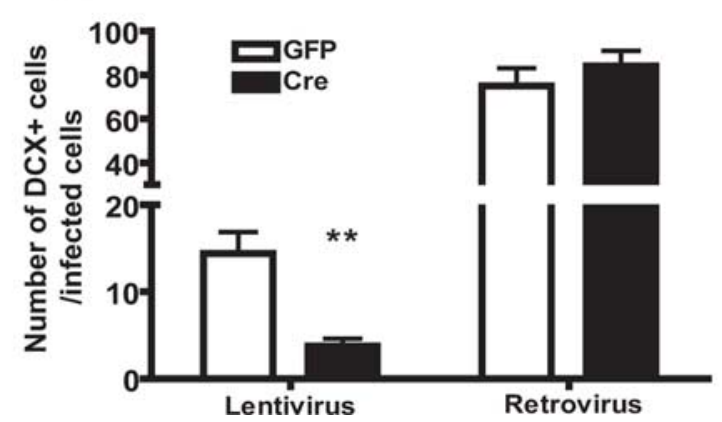

Figure 7. Deletion of Smad4 in stem cells or transit-amplifying cells results in different phenotypes. $\boldsymbol{A}$, Histogram depicting the identity of GFP-positive cells $2 \mathrm{~d}$ after injection of retroviral or lentiviral vectors into the adult SEZ, respectively. Note that retroviral mediated gene transfer occurs only in fast proliferating cells (transit-amplifying precursors and $D C X+$ neuroblasts), but not in astrocytes and stem cells. The latter are preferentially targeted by lentiviral vectors. $\boldsymbol{B}$, Lineage diagram depicting viral-specific targeting. $\boldsymbol{C}-\boldsymbol{F}$, Fluorescent micrographs of GFP + cells infected with lentiviral $(\boldsymbol{C}, \boldsymbol{D})$ or retroviral $(\boldsymbol{E}, \boldsymbol{F})$ vectors double-stained for $D C X 7 \mathrm{~d}$ after injection. Note that fewer $\mathrm{Cre}+/ D C X+$ cells were observed when Crecontaining lentivirus $(\boldsymbol{D})$, but not Cre-containing retrovirus was used $(\boldsymbol{F})$. Examples of doublepositive cells are indicated by arrows. $\boldsymbol{G}$, Histogram depicting the number of $D C X+$ neuroblasts among lentiviral and retroviral infected GFP or Cre + cells in the adult SEZ of homozygous floxed Smad4 mice $7 \mathrm{~d}$ after injection. Note the strong reduction of neuroblasts generated from lentivirus Cre-infected cells, whereas the neuroblast progeny of retrovirus Cre-infected cells was not affected. (Lentivirus: $n$ (animals) $=10 ; n$ (cells): GFP $=572$, Cre $=830$; retrovirus: $n$ (animals) $=6 ; n$ (cells): GFP $=372$, (re $=559$.) Error bars indicate SEM. ${ }^{* *} p<0.01$. Scale bar: (in F) $C, D, 50 \mu \mathrm{m} ; E, F, 40 \mu \mathrm{m}$. 
Indeed, on injection of MLV-based retroviral vectors containing GFP into the SEZ, virtually no GFP + cells were GFAP + $2 \mathrm{~d}$ (Fig. $7 A$ ) or 7 d later (Hack et al., 2005), indicating that neural stem cells were not targeted. In contrast, on injection of lentiviral vectors containing GFP (Pfeifer et al., 2001, 2002), the vast majority of GFP + cells are GFAP $+2 \mathrm{~d}$ after viral injection (Fig. $7 A$ ). We therefore used these viral vectors to target Cre to distinct stem or progenitor populations in Smad4fl/fl mice (Fig. $7 B$ ). Indeed, $7 \mathrm{~d}$ after injection of lentivirus containing Cre into the SEZ of Smad $4 \mathrm{fl} / \mathrm{fl}$ mice, a strong reduction in the number of DCX + cells was detected among the Cre-infected cells to less than one-third of the DCX+ cells among cells infected by the GFP-containing control virus (Fig. 7C,D,G). In contrast, however, MLVretrovirus-mediated deletion of $\operatorname{Smad} 4$ by Cre expression in TAPs and neuroblasts of Smad4fl/fl mice did not show any effect on the number of DCX + neuroblasts $7 \mathrm{~d}$ after injection (Fig. $7 E-G)$. Thus, these data suggest a role for $\operatorname{Smad} 4$ at an early stage in the adult neural stem cell-derived neurogenesis.

\section{Interference with BMP- but not TGF $\beta$-mediated signaling increases Olig2 and decreases neurogenesis}

The above results have shown a role of Smad4 in suppressing the oligodendroglial lineage when TAPs are generated. Although this phenotype is consistent with the identity of BMP-responsive cell types, the stem cells and TAPs, it may also be caused by TGF $\beta$ mediated signaling because Smad4 is a central mediator of both TGF $\beta$ and BMP signaling (Attisano and Wrana, 2002). Indeed, we also detected phosphorylated Smad 2 and 3, the receptorregulated Smads of TGF $\beta$ signaling in the adult SEZ (supplemental Fig. 5A, $B$, available at www.jneurosci.org as supplemental material). We therefore aimed to discriminate the role of the BMP or TGF $\beta$ pathway, respectively. To block the BMP selectively, we used minipumps to infuse Noggin, an extracellular inhibitor binding to BMP ligands, but not to TGF $\beta$ (Zimmerman et al., 1996; Brunet et al., 1998; Shi and Massague, 2003), for $7 \mathrm{~d}$ into the lateral ventricle of WT mice. When mice were examined $3 \mathrm{~d}$ after the end of infusion, p-Smad1/5/8 immunostaining showed a severe decrease in the SEZ after Noggin, but not after vehicle (aCSF) infusion (Fig. 8A,D), confirming the successful delivery of Noggin. The number of DCX + cells in the SEZ decreased after Noggin infusion to less than one-half the number observed in animals receiving vehicle infusion (Fig. $8 B, E, G$ ). In additional agreement with the results obtained after Smad 4 deletion, Noggin infusion also increased the number of Olig2 + cells to double the number obtained after vehicle infusion (Fig. $8 C, F, G)$. Together, the blockade of BMP signaling phenocopies the main defects observed after deletion of Smad4, suggesting that BMP is the main neurogenic signal in this regard.

However, we may have missed some contribution of the TGF $\beta$-mediated pathway by comparing the Smad 4 genetic deletion and Noggin infusion. Therefore, we directly interfered with TGF $\beta$ signaling by crossing the GLAST:CreERT 2 mouse line with a mouse line carrying floxed alleles for the only type II receptor of this pathway (Tgfbr2fl/fl) that is therefore required to mediate TGF $\beta$ signaling (Leveen et al., 2002). Animals were analyzed 3 months after tamoxifen application, because only then Tgfbr2 immunoreactivity had disappeared (supplemental Fig. 6A,D, available at www.jneurosci.org as supplemental material) (data not shown). However, even at this late stage, we could not detect any significant changes in the number of neuroblasts or Olig2+ cells (supplemental Fig. 6, available at www.jneurosci.org as supplemental material). Thus, TGF $\beta$-mediated signaling does not contribute to the striking decrease in neurogenesis and diversion of the adult stem cell progeny toward an oligodendroglial fate observed after Smad4 deletion.

\section{Discussion}

Here, we demonstrate that BMP signaling is active in neural stem cells and TAPs and required for adult neurogenesis in the adult SEZ. Our results show that both genetic deletion of Smad4 and infusion of Noggin resulted in an increase in Olig2 + oligodendrocyte precursors at the expense of neurogenesis. This decrease in neurogenesis could be fully rescued by suppression of Olig2 function. Smad4-mediated BMP signaling is required in a cellautonomous manner at an early stage in the adult neural stem cell lineage when stem cells give rise to TAPs. Our results therefore imply BMP as one of the earliest key signals in the adult neural stem cell niche allowing the progression toward the neurogenic lineage by inhibiting the generation of oligodendrocytes.

\section{Smad4-mediated BMP signaling positively regulates neurogenesis in the adult neural stem cell niche}

Here, we propose the BMP-mediated Smad pathway as one of the key factors promoting neurogenesis in the unique neurogenic environment of the SEZ, but not the SGZ. Using two independent means, nuclear localization of $\mathrm{p}$-Smads $1 / 5 / 8$ and BREdriven reporter activity, we demonstrated the activity of the Smad pathway-dependent BMP signaling in adult neural stem cells and TAPs. This activity is present close to the ependymal layer despite the expression of Noggin in ependymal cells (Lim et al., 2000; Peretto et al., 2004). Thus, rather than fully blocking the binding of BMP ligands to their receptors, Noggin secretion may adjust the level of BMP signaling activity. This adjustment may also depend on the amount and identity of BMP ligands secreted. For example, BMP7, one of the ligands expressed in the adult SEZ, is relatively insensitive to Noggin (Zimmerman et al., 1996). Because different concentrations of BMP are known to exert different effects, a tight balance between BMP ligands and inhibitors of this pathway is particularly important. For example, higher levels of BMP promote cell death and inhibit proliferation of embryonic cortex precursors (Mehler et al., 2000; Hebert et al., 2002), whereas lower concentrations promoted neuronal and astroglial differentiation and inhibited oligodendrogliogenesis (Mabie et al., 1999; Chojnacki and Weiss, 2004). Thus, the level of BMP signaling may also be critical in the adult SEZ. Indeed, when Lim et al. (2000) overexpressed BMP7 in the ependymal cells, they observed a decrease in proliferation that may be responsible for the decrease in regeneration of neuroblasts after AraC and BMP7 treatment observed by these authors. Recent data also demonstrated the antiproliferative role of BMP overexpression on the proliferation of glioblastoma cells in the adult brain (Piccirillo et al., 2006). Additionally, particularly high levels of BMP may also act via Smad-independent pathways (Rajan et al., 2003; Nohe et al., 2004). These considerations therefore imply that raising the levels of BMP may not necessarily reveal the endogenous function of BMP signaling at the physiological levels. Indeed, lowering the levels of BMP signaling by Noggin infusion or Smad4 deletion did not affect proliferation, consistent with only high levels of BMP acting on proliferation.

Given the importance of a precise level of BMP-signaling activity, one may gain better insights by interfering with the endogenous levels of BMP or its signaling mediators. Our results obtained by lowering the levels of BMP activity by Noggin infusion into the ventricle or deleting the essential signaling mediator Smad4 revealed the generation of oligodendrocytes at the expense of neurogenesis. These findings suggest that the endoge- 


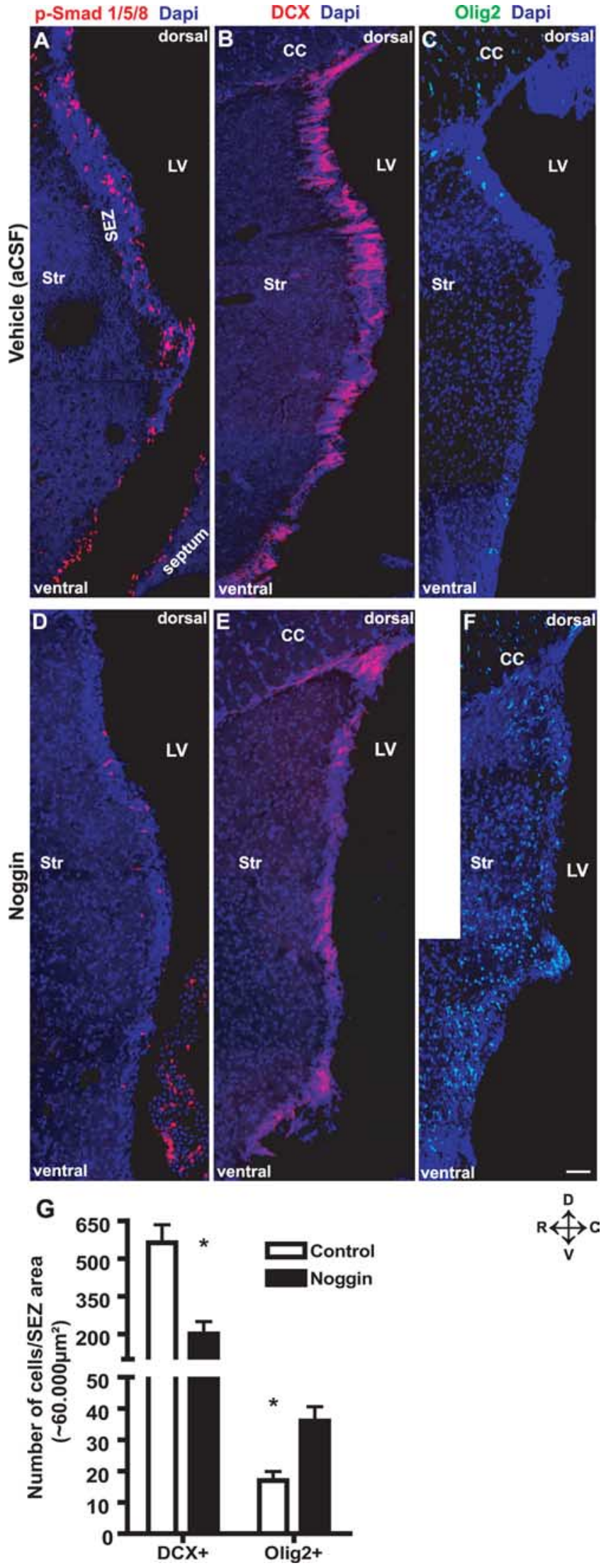

Figure 8. Noggin infusion inhibits adult neurogenesis and upregulates 0lig2. $A-F$, Fluorescent micrographs depicting p-Smad1/5/8+(A,D), DCX $+(\boldsymbol{B}, \boldsymbol{E})$, and 0lig2 $+(\boldsymbol{C}, \boldsymbol{F})$ cells in the SEZ $10 \mathrm{~d}$ ( $7 \mathrm{~d}$ infusion plus $3 \mathrm{~d}$ survival) after aCSF $(\boldsymbol{A}-\boldsymbol{C})$ or infusion of the extracellular inhibitor of BMP ligands, Noggin $(\boldsymbol{D}-\boldsymbol{F})$ into the lateral ventricle of WT mice. Note the loss of nuclear $\mathrm{p}$-Smad1/5/8 staining after Noggin infusion in $\boldsymbol{D}$ compared with control in $\boldsymbol{A}$. Note the severe nous role of BMP signaling is to allow neurogenesis by suppressing oligodendrogliogenesis. The endogenous levels of Noggin expressed in the ependymal cells of the adult SEZ may therefore be crucial to allow the low degree of oligodendrogliogenesis occurring normally (Hack et al., 2005; Menn et al., 2006). Interestingly, oligodendrogliogenesis in the SEZ increases after demyelination (Nait-Oumesmar et al., 1999, 2007), indicating that alterations in the stem cell niche may mediate the injurytriggered signaling. Together, our results imply that the finetuning of progenitors specified toward neurogenesis or oligodendrogliogenesis crucially depends on BMP-mediated signaling.

Consistent with our observations in the adult SEZ, BMP signaling inhibits and Noggin application promotes oligodendrogliogenesis in the developing nervous system (Hardy and Friedrich, 1996; Kondo and Raff, 2000; Mekki-Dauriac et al., 2002; Gomes et al., 2003; Samanta and Kessler, 2004). Interestingly, the inhibition of oligodendrogliogenesis observed during development occurs sometimes in favor of neurogenesis (Mabie et al., 1999; Schneider et al., 1999; Muller and Rohrer, 2002; Chojnacki and Weiss, 2004), and sometimes in favor of astroglial differentiation (Gross et al., 1996; Gomes et al., 2003). A potential molecular mechanism mediating these diverse effects may be the difference in activity of signal transducer and activator of transcription (STAT)-mediated transcription. BMP-mediated effects on astroglial differentiation are thought to be mediated via the STAT signaling pathway (Yanagisawa et al., 2001; Rajan et al., 2003) that is not active in the adult neural stem cell zone (Bauer and Patterson, 2006). This may explain why BMP does not promote astrogliogenesis in the adult SEZ. Notably, the STATsignaling pathway is activated after injury in the brain parenchyma (Okada et al., 2006; Fuller et al., 2007). Therefore, the coactivation of STAT and Smad-signaling may explain why BMP promotes astroglial fate in the injured brain parenchyma (Okada et al., 2006; Fuller et al., 2007) and why overexpression of Noggin in the striatal or spinal cord parenchyma (causing injury by injection of the viral vectors) allows transplanted neurosphere cells to differentiate into neurons (Lim et al., 2000; Setoguchi et al., 2004). Instead, in the adult SEZ where STAT signaling seems not to be active, endogenous BMP-mediated signaling via Smad4 promotes neurogenesis and inhibits oligodendrogliogenesis.

\section{Smad4 acts early in the lineage within the adult SEZ}

A particularly interesting aspect of our findings is that Smad4mediated BMP signaling promotes neurogenesis at very early stages of the lineage. This is evident from the finding that deletion of Smad 4 in TAPs and neuroblasts by retroviral expression of Cre had no immediate effect on neurogenesis, whereas deletion of Smad 4 by a lentiviral vector in stem and progenitor cells resulted in a decrease in neurogenesis. Thus, Smad4-mediated signaling apparently promotes neurogenesis before the formation of neuroblasts at the level of the stem cells, when the identity of the TAPs is determined. This effect is different from previous effects on adult neural stem cells that mostly altered their proliferation and thereby affected neurogenesis (Ramirez-Castillejo et al., 2006; Sakaguchi et al., 2006). We therefore conclude that Smad4-

reduction in neuroblasts in $\boldsymbol{B}$ and $\boldsymbol{E}$ and, conversely, the increase in the number of 0 lig2 + cells in $\boldsymbol{C}$ and $\boldsymbol{F}$ after Noggin infusion as depicted in the histogram $\boldsymbol{G}$ [for DCX, $n$ (cells) $=13,516$ (vehicle), 4833 (Noggin), 3 animals each; and for 0lig2, $n$ (cells) = 168 (vehicle), 332 (Noggin), 3 animals each]. Error bars indicate SEM. ${ }^{*} p<0.05$. LV, Lateral ventricle; Str, striatum; D, dorsal; V, ventral; $R$, rostral; C, caudal. Scale bar: (in $\boldsymbol{F}) \boldsymbol{A}, \boldsymbol{C}, \boldsymbol{D}, \boldsymbol{F}, 100 \mu \mathrm{m} ; \boldsymbol{B}, \boldsymbol{E}, 120 \mu \mathrm{m}$. 
mediated transcription is required at the transition from stem cells to TAPs.

\section{Neurogenesis results from inhibition of oligodendrogenesis in the adult brain}

Interestingly, however, interference with Smad4 did not cause a failure to upregulate the key neurogenic factors, such as Pax6 (Hack et al., 2005) and Dlx2 (Doetsch et al., 2002; Petryniak et al., 2007) but rather lead to the ectopic upregulation of Olig2. Thus, other signals must be crucial for upregulation of these neurogenic transcription factors, whereas Smad4-mediated transcription is crucial to suppress Olig2 and thereby restrict the oligodendroglial lineage. Strikingly, suppression of Olig2 function by the Olig2VP16 construct was sufficient to rescue the defects in neurogenesis observed after Smad4 deletion, consistent with the remnant neurogenic potential in these cells in the absence of Olig2 upregulation. These data henceforth imply the regulation of the transcription factor Olig2 as a key determinant for the choice between a neuronal or oligodendroglial lineage in the adult neural stem cell-derived progeny, reminiscent of its role in development (Doetsch et al., 2002; Ligon et al., 2006; Petryniak et al., 2007). Moreover, these data also suggest that TAPs and neuroblasts are not yet irreversibly committed to their fate, because their fate cannot only be altered by overexpression of Olig2 (Hack et al., 2005) but also by transplantation of PSA-NCAM + neuroblasts outside the neurogenic niche (Seidenfaden et al., 2006). These data therefore underline the importance of a signaling mechanism maintaining TAPs and neuroblasts within the neurogenic lineage and suppressing Olig2.

Our data imply Smad4-mediated BMP signaling as a key factor for this role. BMP ligands and BMP-specific p-Smads are expressed in the SEZ, but not in the RMS. Moreover, BMPspecific p-Smads are detectable only in stem cells and TAPs, but not in neuroblasts. Finally, blocking of BMP signaling via Noggin also leads to the upregulation of Olig2, whereas interference with the TGF $\beta$ pathway did not, demonstrating the key role of BMPmediated signaling in the suppression of Olig2. The observation that this pathway is present and required at early stages in the stem cell-derived lineage, is consistent with the need of Olig2 suppression at these early stages in the lineage (Hack et al., 2005). Our data therefore imply BMP-mediated signaling as one of the earliest factors in the adult neural stem cell niche to direct the immediate progeny of stem cells toward a neurogenic fate by blocking progression toward the oligodendroglial lineage. Notably, outside the neurogenic niche, virtually all progenitors are oligodendrocyte progenitors in the adult mammalian brain (Horner et al., 2002; Dawson et al., 2003) and suppression of Olig2 function in these cells in the cortical parenchyma also leads to upregulation of Pax6 and neurogenesis (Buffo et al., 2005). One may therefore speculate that a key aspect of the adult neurogenic niche is to suppress oligodendrogliogenesis, the apparent default pathway in the adult mammalian brain.

\section{References}

Alvarez-Buylla A, Garcia-Verdugo JM, Tramontin AD (2001) A unified hypothesis on the lineage of neural stem cells. Nat Rev Neurosci 2:287-293.

Attisano L, Wrana JL (2002) Signal transduction by the TGF-beta superfamily. Science 296:1646-1647.

Balordi F, Fishell G (2007) Hedgehog signaling in the subventricular zone is required for both the maintenance of stem cells and the migration of newborn neurons. J Neurosci 27:5936-5947.

Bauer S, Patterson PH (2006) Leukemia inhibitory factor promotes neural stem cell self-renewal in the adult brain. J Neurosci 26:12089-12099.

Berninger B, Guillemot F, Gotz M (2007) Directing neurotransmitter iden- tity of neurones derived from expanded adult neural stem cells. Eur J Neurosci 25:2581-2590.

Brunet LJ, McMahon JA, McMahon AP, Harland RM (1998) Noggin, cartilage morphogenesis, and joint formation in the mammalian skeleton. Science 280:1455-1457.

Buffo A, Vosko MR, Erturk D, Hamann GF, Jucker M, Rowitch D, Gotz M (2005) Expression pattern of the transcription factor Olig2 in response to brain injuries: implications for neuronal repair. Proc Natl Acad Sci USA 102:18183-18188.

Chojnacki A, Weiss S (2004) Isolation of a novel platelet-derived growth factor-responsive precursor from the embryonic ventral forebrain. J Neurosci 24:10888-10899.

Coskun V, Venkatraman G, Yang H, Rao MS, Luskin MB (2001) Retroviral manipulation of the expression of bone morphogenetic protein receptor Ia by SVZa progenitor cells leads to changes in their p19(INK4d) expression but not in their neuronal commitment. Int J Dev Neurosci 19:219-227.

Dawson MR, Polito A, Levine JM, Reynolds R (2003) NG2-expressing glial progenitor cells: an abundant and widespread population of cycling cells in the adult rat CNS. Mol Cell Neurosci 24:476-488.

Doetsch F, Petreanu L, Caille I, Garcia-Verdugo JM, Alvarez-Buylla A (2002) EGF converts transit-amplifying neurogenic precursors in the adult brain into multipotent stem cells. Neuron 36:1021-1034.

Fan X, Xu H, Cai W, Yang Z, Zhang J (2003) Spatial and temporal patterns of expression of Noggin and BMP4 in embryonic and postnatal rat hippocampus. Brain Res Dev Brain Res 146:51-58.

Fuller ML, Dechant AK, Rothstein B, Caprariello A, Wang R, Hall AK, Miller RH (2007) Bone morphogenetic proteins promote gliosis in demyelinating spinal cord lesions. Ann Neurol 62:288-300.

Gates MA, Thomas LB, Howard EM, Laywell ED, Sajin B, Faissner A, Gotz B, Silver J, Steindler DA (1995) Cell and molecular analysis of the developing and adult mouse subventricular zone of the cerebral hemispheres. J Comp Neurol 361:249-266.

Gomes WA, Mehler MF, Kessler JA (2003) Transgenic overexpression of BMP4 increases astroglial and decreases oligodendroglial lineage commitment. Dev Biol 255:164-177.

Gross RE, Mehler MF, Mabie PC, Zang Z, Santschi L, Kessler JA (1996) Bone morphogenetic proteins promote astroglial lineage commitment by mammalian subventricular zone progenitor cells. Neuron 17:595-606.

Hack MA, Saghatelyan A, de Chevigny A, Pfeifer A, Ashery-Padan R, Lledo PM, Gotz M (2005) Neuronal fate determinants of adult olfactory bulb neurogenesis. Nat Neurosci 8:865-872.

Hardy RJ, Friedrich Jr VL (1996) Oligodendrocyte progenitors are generated throughout the embryonic mouse brain, but differentiate in restricted foci. Development 122:2059-2069.

Hebert JM, Mishina Y, McConnell SK (2002) BMP signaling is required locally to pattern the dorsal telencephalic midline. Neuron 35:1029-1041.

Horner PJ, Thallmair M, Gage FH (2002) Defining the NG2-expressing cell of the adult CNS. J Neurocytol 31:469-480.

Jackson EL, Garcia-Verdugo JM, Gil-Perotin S, Roy M, Quinones-Hinojosa A, VandenBerg S, Alvarez-Buylla A (2006) PDGFR alpha-positive B cells are neural stem cells in the adult SVZ that form glioma-like growths in response to increased PDGF signaling. Neuron 51:187-199.

Johansson CB, Momma S, Clarke DL, Risling M, Lendahl U, Frisen J (1999) Identification of a neural stem cell in the adult mammalian central nervous system. Cell 96:25-34.

Kohwi M, Osumi N, Rubenstein JL, Alvarez-Buylla A (2005) Pax6 is required for making specific subpopulations of granule and periglomerular neurons in the olfactory bulb. J Neurosci 25:6997-7003.

Kondo T, Raff M (2000) Oligodendrocyte precursor cells reprogrammed to become multipotential CNS stem cells. Science 289:1754-1757.

Leveen P, Larsson J, Ehinger M, Cilio CM, Sundler M, Sjostrand LJ, Holmdahl R, Karlsson S (2002) Induced disruption of the transforming growth factor beta type II receptor gene in mice causes a lethal inflammatory disorder that is transplantable. Blood 100:560-568.

Ligon KL, Fancy SP, Franklin RJ, Rowitch DH (2006) Olig gene function in CNS development and disease. Glia 54:1-10.

Lim DA, Tramontin AD, Trevejo JM, Herrera DG, Garcia-Verdugo JM, Alvarez-Buylla A (2000) Noggin antagonizes BMP signaling to create a niche for adult neurogenesis. Neuron 28:713-726.

Mabie PC, Mehler MF, Kessler JA (1999) Multiple roles of bone morphoge- 
netic protein signaling in the regulation of cortical cell number and phenotype. J Neurosci 19:7077-7088.

Mehler MF, Mabie PC, Zhu G, Gokhan S, Kessler JA (2000) Developmental changes in progenitor cell responsiveness to bone morphogenetic proteins differentially modulate progressive CNS lineage fate. Dev Neurosci 22:74-85.

Mekki-Dauriac S, Agius E, Kan P, Cochard P (2002) Bone morphogenetic proteins negatively control oligodendrocyte precursor specification in the chick spinal cord. Development 129:5117-5130.

Menn B, Garcia-Verdugo JM, Yaschine C, Gonzalez-Perez O, Rowitch D, Alvarez-Buylla A (2006) Origin of oligodendrocytes in the subventricular zone of the adult brain. J Neurosci 26:7907-7918.

Ming GL, Song H (2005) Adult neurogenesis in the mammalian central nervous system. Annu Rev Neurosci 28:223-250.

Mizuguchi R, Sugimori M, Takebayashi H, Kosako H, Nagao M, Yoshida S, Nabeshima Y, Shimamura K, Nakafuku M (2001) Combinatorial roles of olig2 and neurogenin2 in the coordinated induction of pan-neuronal and subtype-specific properties of motoneurons. Neuron 31:757-771.

Mori T, Tanaka K, Buffo A, Wurst W, Kuhn R, Gotz M (2006) Inducible gene deletion in astroglia and radial glia-a valuable tool for functional and lineage analysis. Glia 54:21-34.

Morshead CM, Reynolds BA, Craig CG, McBurney MW, Staines WA, Morassutti D, Weiss S, van der Kooy D (1994) Neural stem cells in the adult mammalian forebrain: a relatively quiescent subpopulation of subependymal cells. Neuron 13:1071-1082.

Muller F, Rohrer H (2002) Molecular control of ciliary neuron development: BMPs and downstream transcriptional control in the parasympathetic lineage. Development 129:5707-5717.

Nait-Oumesmar B, Decker L, Lachapelle F, Avellana-Adalid V, Bachelin C, Van Evercooren AB (1999) Progenitor cells of the adult mouse subventricular zone proliferate, migrate and differentiate into oligodendrocytes after demyelination. Eur J Neurosci 11:4357-4366.

Nait-Oumesmar B, Picard-Riera N, Kerninon C, Decker L, Seilhean D, Hoglinger GU, Hirsch EC, Reynolds R, Baron-Van Evercooren A (2007) Activation of the subventricular zone in multiple sclerosis: evidence for early glial progenitors. Proc Natl Acad Sci USA 104:4694-4699.

Ninkovic J, Gotz M (2007) Signaling in adult neurogenesis: from stem cell niche to neuronal networks. Curr Opin Neurobiol 17:338-344.

Nohe A, Keating E, Knaus P, Petersen NO (2004) Signal transduction of bone morphogenetic protein receptors. Cell Signal 16:291-299.

Nolte C, Matyash M, Pivneva T, Schipke CG, Ohlemeyer C, Hanisch UK, Kirchhoff F, Kettenmann H (2001) GFAP promoter-controlled EGFPexpressing transgenic mice: a tool to visualize astrocytes and astrogliosis in living brain tissue. Glia 33:72-86.

Okada S, Nakamura M, Katoh H, Miyao T, Shimazaki T, Ishii K, Yamane J, Yoshimura A, Iwamoto Y, Toyama Y, Okano H (2006) Conditional ablation of Stat 3 or Socs 3 discloses a dual role for reactive astrocytes after spinal cord injury. Nat Med 12:829-834.

Parras CM, Galli R, Britz O, Soares S, Galichet C, Battiste J, Johnson JE, Nakafuku M, Vescovi A, Guillemot F (2004) Mash1 specifies neurons and oligodendrocytes in the postnatal brain. EMBO J 23:4495-4505.

Peretto P, Cummings D, Modena C, Behrens M, Venkatraman G, Fasolo A, Margolis FL (2002) BMP mRNA and protein expression in the developing mouse olfactory system. J Comp Neurol 451:267-278.

Peretto P, Dati C, De Marchis S, Kim HH, Ukhanova M, Fasolo A, Margolis FL (2004) Expression of the secreted factors noggin and bone morphogenetic proteins in the subependymal layer and olfactory bulb of the adult mouse brain. Neuroscience 128:685-696.

Petryniak MA, Potter GB, Rowitch DH, Rubenstein JL (2007) Dlx1 and Dlx2 control neuronal versus oligodendroglial cell fate acquisition in the developing forebrain. Neuron 55:417-433.

Pfeifer A, Brandon EP, Kootstra N, Gage FH, Verma IM (2001) Delivery of the Cre recombinase by a self-deleting lentiviral vector: efficient gene targeting in vivo. Proc Natl Acad Sci USA 98:11450-11455.
Pfeifer A, Ikawa M, Dayn Y, Verma IM (2002) Transgenesis by lentiviral vectors: lack of gene silencing in mammalian embryonic stem cells and preimplantation embryos. Proc Natl Acad Sci USA 99:2140-2145.

Piccirillo SG, Reynolds BA, Zanetti N, Lamorte G, Binda E, Broggi G, Brem H, Olivi A, Dimeco F, Vescovi AL (2006) Bone morphogenetic proteins inhibit the tumorigenic potential of human brain tumour-initiating cells. Nature 444:761-765.

Rajan P, Panchision DM, Newell LF, McKay RD (2003) BMPs signal alternately through a SMAD or FRAP-STAT pathway to regulate fate choice in CNS stem cells. J Cell Biol 161:911-921.

Ramirez-Castillejo C, Sanchez-Sanchez F, Andreu-Agullo C, Ferron SR, Aroca-Aguilar JD, Sanchez P, Mira H, Escribano J, Farinas I (2006) Pigment epithelium-derived factor is a niche signal for neural stem cell renewal. Nat Neurosci 9:331-339.

Rhee JM, Pirity MK, Lackan CS, Long JZ, Kondoh G, Takeda J, Hadjantonakis AK (2006) In vivo imaging and differential localization of lipidmodified GFP-variant fusions in embryonic stem cells and mice. Genesis 44:202-218.

Saghatelyan A, de Chevigny A, Schachner M, Lledo PM (2004) Tenascin-R mediates activity-dependent recruitment of neuroblasts in the adult mouse forebrain. Nat Neurosci 7:347-356.

Sakaguchi M, Shingo T, Shimazaki T, Okano HJ, Shiwa M, Ishibashi S, Oguro H, Ninomiya M, Kadoya T, Horie H, Shibuya A, Mizusawa H, Poirier F, Nakauchi H, Sawamoto K, Okano H (2006) A carbohydrate-binding protein, Galectin-1, promotes proliferation of adult neural stem cells. Proc Natl Acad Sci USA 103:7112-7117.

Samanta J, Kessler JA (2004) Interactions between ID and OLIG proteins mediate the inhibitory effects of BMP4 on oligodendroglial differentiation. Development 131:4131-4142.

Schneider C, Wicht H, Enderich J, Wegner M, Rohrer H (1999) Bone morphogenetic proteins are required in vivo for the generation of sympathetic neurons. Neuron 24:861-870.

Seidenfaden R, Desoeuvre A, Bosio A, Virard I, Cremer H (2006) Glial conversion of SVZ-derived committed neuronal precursors after ectopic grafting into the adult brain. Mol Cell Neurosci 32:187-198.

Setoguchi T, Nakashima K, Takizawa T, Yanagisawa M, Ochiai W, Okabe M, Yone K, Komiya S, Taga T (2004) Treatment of spinal cord injury by transplantation of fetal neural precursor cells engineered to express BMP inhibitor. Exp Neurol 189:33-44.

Shi Y, Massague J (2003) Mechanisms of TGF-beta signaling from cell membrane to the nucleus. Cell 113:685-700.

Shihabuddin LS, Horner PJ, Ray J, Gage FH (2000) Adult spinal cord stem cells generate neurons after transplantation in the adult dentate gyrus. J Neurosci 20:8727-8735.

Soriano P (1999) Generalized lacZ expression with the ROSA26 Cre reporter strain. Nat Genet 21:70-71.

Wrana JL (2000) Crossing Smads. Sci STKE 2000:RE1.

Yanagisawa M, Nakashima K, Takizawa T, Ochiai W, Arakawa H, Taga T (2001) Signaling crosstalk underlying synergistic induction of astrocyte differentiation by BMPs and IL-6 family of cytokines. FEBS Lett 489:139-143.

Yang X, Li C, Xu X, Deng C (1998) The tumor suppressor SMAD4/DPC4 is essential for epiblast proliferation and mesoderm induction in mice. Proc Natl Acad Sci USA 95:3667-3672.

Yang X, Li C, Herrera PL, Deng CX (2002) Generation of Smad4/Dpc4 conditional knockout mice. Genesis 32:80-81.

Young KM, Merson TD, Sotthibundhu A, Coulson EJ, Bartlett PF (2007) p75 neurotrophin receptor expression defines a population of BDNFresponsive neurogenic precursor cells. J Neurosci 27:5146-5155.

Zimmerman LB, De Jesus-Escobar JM, Harland RM (1996) The Spemann organizer signal noggin binds and inactivates bone morphogenetic protein 4. Cell 86:599-606. 